\title{
El Marquesado del Valle de Tojo: patrimonio y mayorazgo. Del siglo XVII al XX en Bolivia y Argentina*
}

\author{
por \\ Ana A. Teruel \\ CONICET y Universidad Nacional de Jujuy, Argentina \\ aateruel13@gmail.com
}

\begin{abstract}
El objetivo del artículo es reconstruir, en la larga duración, los cambios y continuidades en el patrimonio territorial del Marquesado del Valle de Tojo en una extensa región a ambos bordes de la actual frontera entre Argentina y Bolivia. El análisis parte de los antecedentes y constitución del mayorazgo, a principios del siglo XVIII, hasta su desestructuración en el último tercio del siglo XIX, y finaliza con una evaluación de las permanencias de esta gran unidad territorial en las estructuras agrarias del Sur de Bolivia y Norte de Argentina en los albores del siglo XX. El estudio se basa en documentación del Archivo del Marquesado del Valle de Tojo, en los catastros republicanos de propiedad territorial de Bolivia y de Argentina; en otras fuentes cualitativas y en estudios previos que permiten una aproximación a la estructura territorial del Marquesado y de la región.

Palabras claves: Marquesado del Valle de Tojo; propiedades; Argentina; Bolivia; permanencias; transformaciones.
\end{abstract}

\section{INTRODUCCIÓN}

Entre los escasos títulos nobiliarios otorgados por la Corona española y los pocos mayorazgos que existieron en los actuales territorios de Argentina

\footnotetext{
* Este trabajo fue realizado en el marco del proyecto PIP CONICET 11420080100473 a mi cargo. Agradezco la atenta lectura y los aportes realizados por Silvia Palomeque a una primera versión de este artículo. No obstante, las afirmaciones aquí vertidas son de mi exclusiva responsabilidad.
} 
y Bolivia ${ }^{1}$, se encuentran los concedidos al Marquesado del Valle de Tojo. Tal fue su poderío que la extensión de sus vastos dominios fue comparada con la de un tercio de la actual Bélgica, a lo que se sumaba la posesión de la más importante encomienda de indios del Tucumán: la de Casabindo y Cochinoca ${ }^{2}$.

Las propiedades del Marquesado, vinculadas por el mayorazgo, constituyeron un espacio integrado económica y socialmente durante casi tres centurias, aún cuando, a comienzos del siglo XIX, las fronteras de los recientes Estados nacionales de Argentina y Bolivia lo dividieran administrativamente. Un mosaico de haciendas y estancias de sus titulares, miembros de la familia Campero, cuyos núcleos principales se hallaban en Tarija (actual Bolivia) y en Yavi (actual provincia de Jujuy, Argentina), cubrían este amplio espacio de tierras situadas en el altiplano (Puna), en los valles intermontanos y en sus bordes selváticos (Yungas).

La peculiaridad e importancia económica, social y política de esta estructura colonial no pasó desapercibida para la historiografía dedicada al Noroeste Argentino. Debemos el primer estudio integral del Marquesado del Valle de Tojo a Guillermo Madrazo ${ }^{3}$, quien trabajó con el archivo del Marquesado depositado en Jujuy (Argentina), centrando su interés especialmente en la porción del antiguo Tucumán y en la encomienda de Casabindo y Cochinoca. Gastón Doucet, también inicialmente interesado en dicha encomienda, se internó en la historia de la familia Campero, convirtiéndose en uno de los mayores especialistas en el tema, notoriamente en el conocimiento de los aspectos genealógicos, jurídicos y sociales ${ }^{4}$.

A pesar de estos importantes antecedentes, hasta el momento de escribir estas líneas no contábamos con una reconstrucción completa del territorio bajo dominio del Marquesado, considerando sus modificaciones a lo largo del tiempo: desde sus orígenes, en el siglo XVI, hasta la desmembración del mayorazgo, en el último tercio del siglo XIX, y el posterior reparto entre sus herederos. Dicha reconstrucción es relevante y necesaria para el conocimiento histórico de la región, pues las permanencias de esa vasta y sólida estructura colonial en la posterior configuración de la propiedad de la tierra y en las relaciones de producción, generaron, hasta el siglo XX, conflictos sociales y políticos.

${ }^{1}$ Para referencias a mayorazgos que existieron en el actual territorio argentino véase Mariluz Urquijo, 1970: 151-152. En cuanto a otros títulos de nobleza en Charcas, ver Quesada Elías, 2001: 129-139. En lo que respecta a los mayorazgos en Charcas del siglo XVI, ver Presta, 2001b: 140-154.

2 Doucet, 2006: 1-3.

${ }^{3}$ Madrazo, 1982: 1-211.

${ }^{4}$ Doucet, 1993: 205-246; 2006: 1-8. 
Uno de los conflictos más conocidos vinculado a las propiedades del antiguo Marquesado fue el que estalló, en la década de 1870, en la Puna de Jujuy, cuando los descendientes de la encomienda de Casabindo y Cochinoca, habiéndose convertido en arrendatarios de la familia Campero, cuestionaron la legitimidad de los títulos del terrateniente y encabezaron una rebelión que se expandió por toda la región. La gran repercusión que tuvo en la época, el enfrentamiento armado con tropas regulares enviadas por el gobierno, la derrota final de los indígenas, en 1875, y el fallo judicial que declaró fiscales las tierras en cuestión, despertó posteriormente el interés de varios investigadores, destacándose Madrazo, Fidalgo y Paz ${ }^{5}$. La Puna de Jujuy volvió a agitarse, en la década de 1920, cuando nuevamente se puso en entredicho la legitimidad de lo títulos de propiedad, no sólo de los fundos que aún pertenecían a los descendientes de Campero, sino también de la gran mayoría de las propiedades de la región ${ }^{6}$. El tema volvió a tornarse conflictivo cuando, en la década de 1930, el ingenio azucarero, San Martín del Tabacal, arrendó dos haciendas que habían pertenecido al Marquesado y continuaban bajo el dominio de sus descendientes: Yavi y Santa Victoria, obligando a sus pobladores a pagar el alquiler de la tierra con su trabajo en la zafra azucarera. Dado que dicha práctica se mantuvo hasta mediados del siglo XX, la cuestión se tornó un tópico clásico en la historiografía del Noroeste Argentino, destacándose los trabajos pioneros de Bisio y Forni y Rutledge ${ }^{7}$, entre muchos otros posteriores.

Me resultó notorio advertir que el conocimiento de los problemas generados por el tipo de estructura agraria heredera del Marquesado concernía especialmente a la porción del territorio que quedó en Argentina; contrariamente, estábamos frente a una casi total ausencia de estudios relativos a las propiedades que habían quedado bajo jurisdicción de Bolivia, desde su constitución como Estado independiente. La frontera internacional establecida entre ambas repúblicas había trazado también una frontera en lo que respecta a los estudios de la propiedad.

Otro asunto que atrajo mi atención fue la constante histórica en los reclamos que realizaban los pobladores, arrendatarios de los latifundios de la actual provincia de Jujuy, en Argentina, invocando sus derechos habidos en la colonia sobre las tierras en cuestión. Recientes estudios referidos al proceso de adquisición de fundos en los siglos XVI y XVII por parte de los colonos

${ }^{5}$ Nos referimos al pionero estudio integral del Marquesado del Valle de Tojo de Madrazo, 1982: 139-176. Al de la rebelión de la Puna de Fidalgo, 1988: 1-116. Y a varios de autoría de Paz sobre el tema, entre ellos pude verse Paz, 1991: 63-89.

${ }^{6}$ Fleitas y Teruel, 2007: 41-61.

7 Bissio y Forni, 1976: 4-21. Rutledge, 1987: 1-297. 
españoles en el actual altiplano jujeño y en las vecinas tierras altas que hoy pertenecen a Bolivia, echaron luz sobre el problema proporcionando importantes elementos de juicio para discernir la cuestión de los derechos de propiedad y comprender el fundamento de los reclamos indígenas. Especialmente destacables son los aportes de Palomeque y Albeck ${ }^{8}$, que documentaron el conjunto de las mercedes de tierras entregadas desde las jurisdicciones coloniales de Charcas y del Tucumán en la región. También referidas a la temprana colonia, las investigaciones de Zanolli sobre la encomienda de Omaguaca ${ }^{9}$, nos brindaron importante información sobre los primeros encomenderos en nuestra región de estudio, sobre el control que ejercieron sobre hombres y tierras y su filiación con la familia Ovando, antecesora de los Marqueses de Tojo. Dichos trabajos, junto con los de otros etnohistoriadores, entre los cuales no puedo dejar de mencionar los estudios de Presta referidos a la ocupación española en el valle de Tarija ${ }^{10}$, me permitieron una mayor comprensión de la documentación de los siglos XIX y XX.

Dado que contamos con importantes antecedentes de investigaciones que trataron, desde distintas ópticas, al Marquesado del Valle de Tojo como objeto específico de estudio, en este artículo planteo como eje de análisis un aspecto que aún no fue abordado en forma integral: la constitución, transformaciones y permanencias, ocurridas en un período de larga duración, de su dominio territorial. Parto de los orígenes y formas de adquisición de las propiedades que quedaron luego vinculadas por el mayorazgo en la jurisdicción colonial de Charcas, pues considero que sobre ese aspecto se fundaron los reiterados conflictos que agitaron al Norte de la actual Argentina. Me abocaré, luego, a la exposición de las transformaciones ocurridas en el siglo XIX para, finalmente, evaluar las permanencias de esta gran unidad territorial en las estructuras agrarias del Sur de Bolivia y Norte de Argentina en los albores del siglo $\mathrm{XX}$.

\section{LOS ORÍGENES}

El origen de esta gran extensión territorial de propiedades se remonta a la fundación de la villa de Tarija en el siglo XVI. Según refiere Presta ${ }^{11}$, en la hueste que acompañó a su fundador, Luis de Fuentes, participaba

\footnotetext{
${ }^{8}$ Palomeque, 2010: 1-77. Albeck y Palomeque, 2009: 173-212.

9 Zanolli, 2005: 1-246.

${ }_{10}$ Presta, 1989: 43-56; 2001a: 25-39.

11 Presta, 2001a: 33-35.
} 
Gutierre Velásquez de Ovando, nombrado por sus servicios Alcalde de la Villa de Tarija, quien pronto se convirtió en uno de los más ricos pobladores recibiendo mercedes de tierras. Si bien la información que poseemos al respecto es fragmentaria, sabemos que las más importantes, Tolomosa y San Mateo, próximas a Tarija, les fueron otorgadas en $15744^{12}$, además de otras en la Quebrada de Humahuaca (actual provincia de Jujuy, Argentina), hacia $1593^{13}$.

Gutierre Velásquez de Ovando contrajo matrimonio con doña Juana de Zárate (hija de Pedro de Zárate, partícipe de las dos primeras fundaciones de la ciudad de Jujuy) con lo cual «se apoyó en la fortuna y alcurnia de su familia política para consolidar la suya» ${ }^{14}$. Zanolli reseña que su cuñado, Juan Ochoa de Zárate, se convertiría en una de las personas más ricas de la Gobernación del Tucumán al recibir la encomienda de Humahuaca, en 1593, $y$ tierras en merced $^{15}$.

Del matrimonio de Gutierre Velásquez de Ovando con Juana de Zárate nacieron siete hijos. Entre ellos nos interesa Pablo Bernárdez de Ovando, quien administró todas las propiedades que dejara su padre hasta la partición de bienes efectuada en 1669 y, al igual que él, aprovechó sus vínculos familiares con los encomenderos de Humahuaca para acceder a la mano de obra indígena ${ }^{16}$.

Pablo Bernárdez de Ovando fundó una gran empresa territorial y de producción que abastecía de tejidos, cueros, carne seca, vinos y otros productos, a las minas de Potosí y Lípez ${ }^{17}$. A las heredades de su padre, sumó las que había recibido en herencia su esposa, Ana María Mogollón de Orosco (nieta de uno de los primeros pobladores de Tarija: Juan Mogollón de Acosta $)^{18}$, y otras que adquirió por diferentes vías, de las cuales sólo conocemos algunas.

12 Madrazo, 1982: 29-32. Campero Paz, 2007: 32-45.

13 Según Sica, 2008: 9, se trataba de mercedes de tierras en la Quebrada de León, otorgadas por su participación en la fundación de la ciudad de Jujuy. Dichas propiedades quedan luego en poder de uno de sus hijos: Pedro Ovando y Zárate.

14 Zanolli, 2005: 135-136.

15 Idem.

16 Gentile, 1994: 217-218.

17 Ibidem: 218

${ }^{18}$ Entre las que había heredado su esposa estaba Chaguaya, en Tarija. Instrucción del Marques del Valle de Tojo Don Martierena a su sobrino Francisco Martierena del Barranco sobre los pleitos que seguía en Tarija sobre Tierras, Archivo Histórico de Jujuy, Marquesado de Tojo, San Salvador de Jujuy, Argentina (AHJ-MT), carpeta 119. 
En 1654 obtuvo la «tercera vida» de la encomienda de Casabindo y Cochinoca, que había quedado vacante, y en 1666, en retribución a su participación en la guerra Calchaquí, se le otorgó el derecho a una vida más. También por sus servicios militares en la «pacificación de la Puna», el gobernador de Tucumán lo nombró Maestre de Campo y, luego, Teniente General del Ejército del Tucumán ${ }^{19}$. Desde el momento en que recibió la encomienda, la hacienda de Yavi pasó a ser su residencia principal ${ }^{20}$.

Bernárdez de Ovando murió en 1676 y dejó como heredera a su única hija viva: Juana Clemencia. Dos años después ésta, que era aún niña, contrajo matrimonio con el Maestre de Campo Juan José Fernández Campero. La vida de la joven fue muy corta, murió sin descendencia en 1690, dejando todos sus bienes, inclusive el derecho a la encomienda, a su marido. Para entonces, Fernández Campero ya había ingresado como Caballero a la Orden de Calatrava ${ }^{21}$. En 1705 obtuvo de Felipe V la prórroga de la encomienda por otras dos vidas más $\mathrm{y}^{22}$, en 1708, el título de Marqués, «otorgado por el rey atendiendo a sus méritos y nobleza y especialmente al servicio de quince mil pesos escudos que el hidalgo tuvo que desembolsar a la Corona» ${ }^{23}$.

Juan José Fernández Campero consolidó la empresa iniciada por Ovando y controló una enorme riqueza proveniente de la producción agropecuaria, del comercio -en una amplísima región desde el Tucumán a Potosí- y de la percepción de tributos y arriendos. Sin duda el gran éxito en el sustento de la estructura del Marquesado del Valle de Tojo se debió al dinamismo que generó la producción minera potosina y, desde el siglo XVIII, la del Sudoeste de la actual Bolivia (Porco, Chichas y Lípez), que con su demanda de mulas,

\footnotetext{
19 Madrazo, 1982: 30-37. Campero Paz, 2007: 32-45.

20 «La encomienda indiana fue, por las dos vidas de su concesión, garante de los derechos y obligaciones señoriales, como también fuente de toda suerte de negocios y oportunidades mercantiles. Entre los derechos del encomendero figuraba la recepción del tributo de sus indios, de quienes podía requerir toda clase de servicios que, aunque fuera de la ley, favorecían la multiplicación de sus negocios. Por otro lado, el señor de indios estaba obligado a ofrecer servicio militar a la corona en el territorio de su jurisdicción y a asegurar el adoctrinamiento y bienestar de sus encomendados. Tales derechos y obligaciones, a más de proporcionarle reconocimiento social, conferían al encomendero participación en las decisiones de la administración local y regional y exclusividad pública al integrar el pequeño círculo de vecinos». Presta, 2001b: 140.

${ }^{21}$ Doucet, 2006: 3.

22 Fernández Campero había solicitado la prórroga de la encomienda para las próximas tres generaciones de sus sucesores, sin embargo, por real Cédula del 22 de junio de 1705 se otorgan sólo dos vidas adicionales. Campero Paz, 2007: 45

${ }^{23}$ Doucet, 2006: 3-4.
} 
vacunos, cereales, vinos y otros productos de consumo, forjó amplios circuitos comerciales que vinculaban a las regiones productoras agropecuarias con los centros mineros ${ }^{24}$. Por otra parte, la posesión de la más importante encomienda de indios del Tucumán le garantizaba no sólo una importante renta a través de la percepción del tributo, sino mano de obra para sostener sus emprendimientos productivos.

\section{Las PROPIEDADES VINCUladAs al MaYorazGo}

Con Juan José Fernández Campero se inició el Marquesado del Valle de Tojo y el mayorazgo que, según disposición testamentaria, se fundó luego de su muerte (acaecida en 1718) sobre los bienes adquiridos, fundamentalmente, por su suegro.

Según expreso deseo testamentario del Marqués, la fundación del mayorazgo quedó a cargo de su heredera, Manuela Micaela Ignacia, cuyo marido, Don Alejo Martierena del Barranco, tomó posesión con el apellido Fernández Campero Martierena del Barranco «aceptando las condiciones de que así él como sus sucesores en el Marquesado usaran los apellidos del primer Marqués y las armas heráldicas del mismo» ${ }^{25}$.

Veamos entonces qué propiedades territoriales quedaban vinculadas según el «Inventario de los bienes que dejó al morir Juan José Fernández Campero de Herrera, Marqués del Valle de Tojo [...] sobre lo que se ha de hacer la escritura de fundación del Mayorazgo» ${ }^{26}$, (cuadro 1). No está de más recordar que el Mayorazgo consistía en un patrimonio perpetuo cuyos poseedores, según un orden sucesorio establecido, no podían enajenarlo sino sólo usufructuar sus rentas $^{27}$. En tanto respondía a una concepción estamental de la sociedad, tenía por objeto asegurar a la nobleza el mantenimiento indiviso de su riqueza, y podía ser instituido por testamento, como es el caso que nos ocupa ${ }^{28}$.

${ }^{24}$ Madrazo, 1982: 117-119.

${ }^{25}$ Doucet, 2006: 4.

${ }^{26}$ Inventario de los bienes que dejó al morir Juan José Fernández Campero de Herrera, Marqués del Valle de Tojo en el año 1718, documento inserto en otro caratulado Testimonio de la hijuela que se le formó a doña Juana Clemencia de Obando de los bienes de su herencia, 1619, AHJ-MT, carpeta 130.

${ }^{27}$ Mariluz Urquijo, 1970: 141.

${ }^{28}$ Doucet, 2006: 2. 
Cuadro 1. Propiedades del Marquesado del Valle de Tojo en 1718

\begin{tabular}{|l|c|}
\hline Bienes raíces & Valor \$ \\
\hline Viña de La Angostura, «con sus ganados, esclavos y aperos» & 67.675 \\
\hline $\begin{array}{l}\text { Chacras y tierras de San Mateo y solares de la villa de Tarija y sus valles, } \\
\text { «cerca de } 300 \text { fanegadas de tierra», «con el servicio de yanaconas que tiene } \\
\text { las referidas chacras» }\end{array}$ & 10.500 \\
\hline «Estancia y tierras de Estumilla con todo lo que le pertenece» & 1.500 \\
\hline $\begin{array}{l}\text { «Valle de Tojo y las tierras de Guanacouno, Santa Ana, Escapana, Río de } \\
\text { San Juan con todos sus aperos, almona y curtiduría» }\end{array}$ & 4.700 \\
\hline $\begin{array}{l}\text { «Casas y tierras de Yavi en que se incluyen las de Sansana con su potrero, } \\
\text { Qungrejos, Cangrejillos, Avra, Río de las Doncellas, San Joseph, Tincuia, } \\
\text { Quirquinchos, Guacoia [Bacoya] y Poscaya hasta la linde de Camacho, valle } \\
\text { denta y Escaya con todos los aperos que hay en ellas» }\end{array}$ & 15.200 \\
\hline «Tierras de Yavi chiquito y treinta fanegadas de tierra sobre Sococha» & 300 \\
\hline Un molino y tierras de la Quebrada Honda «que constan de título» & 2.000 \\
\hline $\begin{array}{l}\text { «Una cuadra y sitio donde estuvieron fabricadas unas casas en la ciudad de } \\
\text { Jujuy» }\end{array}$ & 300 \\
\hline «Dos casas casi arruinadas que hay en Lípez» & 300 \\
\hline
\end{tabular}

Fuente: Elaborado en base a AHJ-MT Inventario de los bienes que dejó al morir Juan José Fernández Campero de Herrera, Marqués del Valle de Tojo en el año 1718.

El dominio del Marquesado se extendía por una amplia región de gran variedad ecológica. Desde el núcleo inicial de Tarija (Bolivia) y sus valles templados, a unos 1.800 metros sobre el nivel del mar en las cuencas de los ríos Tarija y Camacho, llegaba, hacia el Sur, por las Sierras Subandinas de Yungas, calurosas y húmedas en la Alta Cuenca del Bermejo, hasta el actual departamento de Santa Victoria, en Salta (Argentina). Al Oeste de Tarija se extendía por la zona alta andina de Yunchará y una porción de la potosina de Chichas, a más de 3.000 metros sobre el nivel del mar, a ambos márgenes del río Sococha-San Juan de Oro, llegando al altiplano o Puna Seca de Jujuy, en Argentina (ver mapa). 
Ubicación de los dominios del Marquesado del VAlle de Tojo SEgúN DIVISIÓN POLÍTICA ACTUAL

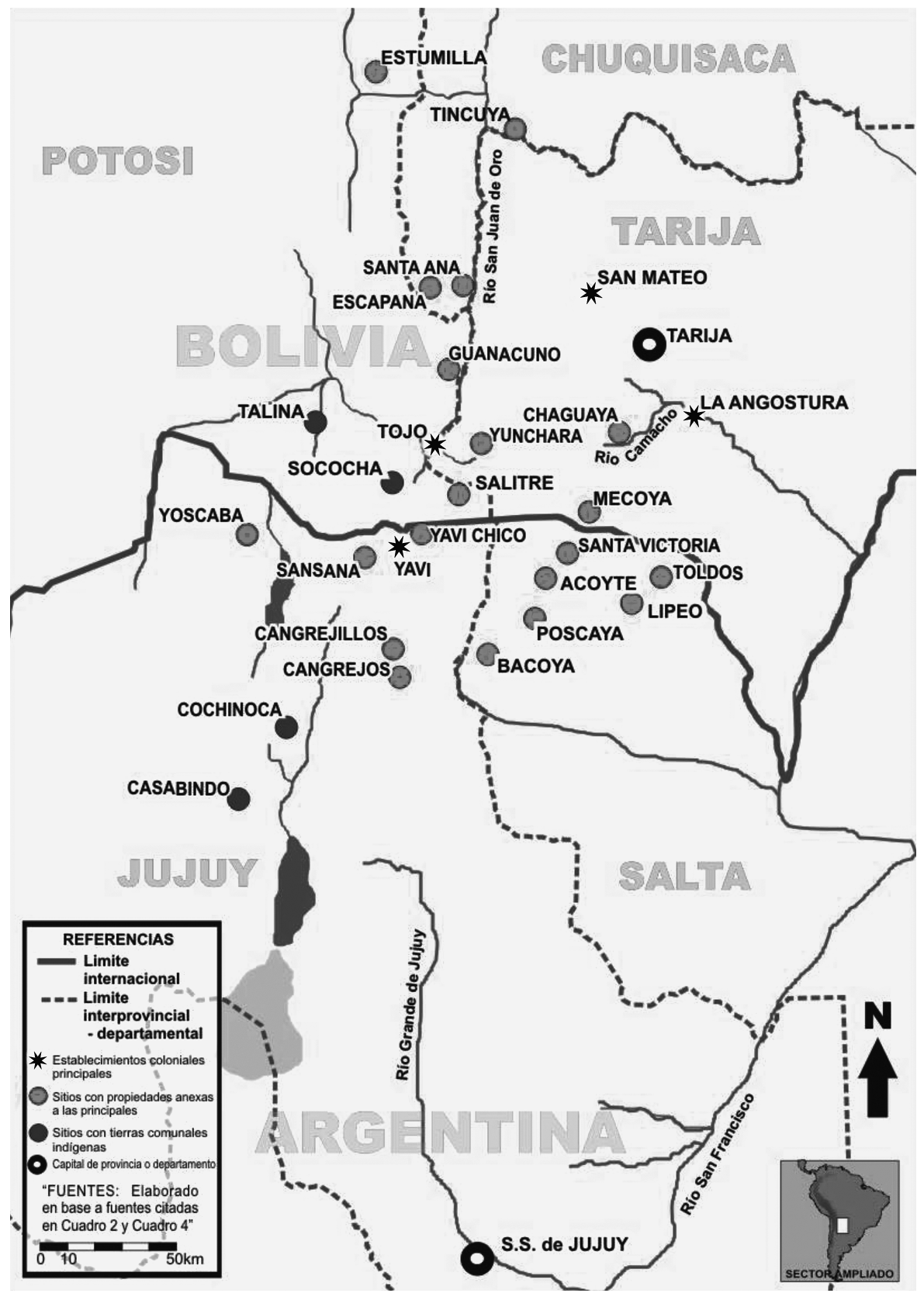


CuAdro 2. Distribución DE LAS PROPIEDAdes SEGÚN PERTENENCIAS JURISDICCIONALES ACTUALES

\begin{tabular}{|c|c|c|c|c|}
\hline \multicolumn{3}{|c|}{ Bolivia } & \multicolumn{2}{|c|}{ Argentina } \\
\hline Tarija & Potosí & Chuquisaca & Jujuy & Salta \\
\hline \multicolumn{5}{|l|}{$\begin{array}{l}\text { La Angostura } \\
\text { (Concepción) }\end{array}$} \\
\hline \multicolumn{5}{|l|}{$\begin{array}{l}\text { San Mateo y } \\
\text { chacras en el } \\
\text { valle de Tarija } \\
\text { (Cercado) }\end{array}$} \\
\hline & $\begin{array}{l}\text { Estumilla } \\
\text { (Nor Chichas) }\end{array}$ & & & \\
\hline Tojo (Yunchara) & $\begin{array}{l}\text { Guanacouno } \\
\text { (Omiste, } \\
\text { Sococha) }\end{array}$ & $\begin{array}{l}\text { Santa Ana } \\
\text { y Escapana } \\
\text { (Sud Cinti) }\end{array}$ & & \\
\hline \multirow[t]{2}{*}{$\begin{array}{l}\text { Tincuya } \\
\text { (Yunchara) } \\
\text { hasta lindar con } \\
\text { Camacho }\end{array}$} & & & $\begin{array}{l}\text { Yavi (Sansana, } \\
\text { Abra, Cangrejos, } \\
\text { Cangrejillos, Río } \\
\text { Doncellas, San José, } \\
\text { Quirquinchos, Escaya) }\end{array}$ & $\begin{array}{l}\text { Bacoya, } \\
\text { Poscaya. } \\
\text { Valle de } \\
\text { Zenta }\end{array}$ \\
\hline & $\begin{array}{l}\text { Sococha } \\
\text { (Omiste) }\end{array}$ & & Yavi Chico & \\
\hline \multicolumn{5}{|l|}{$\begin{array}{l}\text { Quebrada } \\
\text { Honda } \\
\text { (Yunchara) }\end{array}$} \\
\hline $\begin{array}{l}\text { Solares y casas } \\
\text { en Tarija }\end{array}$ & $\begin{array}{l}\text { Casas en } \\
\text { Lípez }\end{array}$ & & $\begin{array}{l}\text { Solares en San } \\
\text { Salvador de Jujuy }\end{array}$ & \\
\hline
\end{tabular}

Fuente: ídem cuadro 1. Observación: en negrita figura el nombre de los establecimientos principales según consta en la fuente.

Características y formas de adquisición de la propiedad

Dedicaré el siguiente apartado a analizar los mecanismos a través de los cuales la familia Ovando/Campero obtuvo sus principales fundos. Considero este aspecto relevante en vistas a sus consecuencias, puesto que los conflictos sociales que se suscitaron en los siglos XIX y XX en torno a la propiedad de 
la tierra pusieron en cuestión, o fueron originados, en los distintos derechos otorgados durante la colonia a indígenas y a españoles.

\section{Tojo y Quebrada Honda}

Como puede apreciarse en el cuadro 2, la propiedad del Valle de Tojo abarcaba parte de Yunchará (Tarija); expandiéndose sobre Guanacouno (Potosí) y Santa Ana y Escapana (Chuquisaca) ${ }^{29}$. Se trata de una región con continuidad ecológica, en la zona alta andina, a ambos márgenes del río Sococha-San Juan de Oro, paso obligado en la ruta que desde Tarija se dirigía a Yavi por la serranía de Sama. Si bien no se trataba de la hacienda más valiosa del Marquesado, era un centro social y productivo importante, con casa señorial, capilla, molino, almona y curtiembre.

Intentar reconstruir el origen de esta propiedad es tarea compleja; hasta el momento quienes se ocuparon de la historia del Marquesado no han aportado mayor información. En el testamento de Pablo Bernárdez de Ovando, del año 1677, consta que entre sus fundos figuraban el Valle de Tojo y la chacra de Santana, con la aclaración de «con todos sus títulos y linderos», como así también Quebrada Honda, vecina de Tojo, «con títulos, composición y confirmación ${ }^{30}$. Madrazo sostuvo que Quebrada Honda fue adquirida por Bernárdez de Ovando mediante compra, en $1647^{31}$, pero no precisa quien fue su anterior dueño; todo parece indicar que se trató de una «composición» sobre tierras ocupadas previamente. Es necesario aclarar que la composición fue un mecanismo oneroso para «perfeccionar» títulos de propiedad o adquirirlos sobre tierras ocupadas de hecho, a la vez que una fuente de recursos financieros para la Corona. En el Virreinato del Perú hubo dos grandes oleadas de composiciones, en 1593-1594 y en 1646-164732.

Respecto a Tojo, en el archivo del Marquesado, depositado en Jujuy, hallé un interesante, aunque muy deteriorado, documento que proporciona información sobre el origen de esta propiedad. Se trata de un pleito, del año 1767, entre «el Marquesado del Valle de Tojo contra Juan Idalgo y Antonio Gutiérrez», por las tierras de Yunchara. En los antecedentes de la cuestión

${ }^{29}$ El sitio denominado Santa Ana, aquí mencionado, no es el que está próximo a la ciudad de Tarija (sobre el río homónimo), sino el que se halla en tierras vecinas a Yunchará, en Sud Cinti.

${ }^{30}$ Agradezco a Silvia Palomeque el haberme facilitado parte de la transcripción del documento que se encuentra en el Archivo General de la Nación, Argentina.

31 Madrazo, 1982: 74.

32 Sobre el tema ver Assadouriam, 2006: 49-50. 
se transcribe una extensa merced de tierras otorgada por Luis de Fuentes, en 1580, a Juan Montaño, entre ellas:

[...] seis fanegadas de tierra de sembradío en el valle de Tojo, desde donde se junta el arroyo de la Quebrada Honda con el Río de San Juan arriba de riego con una estancia encima llamada Yunchara de una legua $[\ldots]^{33}$.

En la documentación consta que Pedro Montaño (posible heredero de Juan Montaño) vendió «las estancia y pastos llamadas el Yunchara que es en los altos del valle de Tojo y Río San Juan» a Alonso Gutiérrez, quien «compuso» sus títulos en 1647 ante el Juez Visitador de Ventas y Composición, Francisco de la Peña ${ }^{34}$. Un siglo más tarde, cuando esas tierras ya estaban incorporadas al Marquesado, se entabló el pleito en el que el Marqués alegó que los títulos de Gutiérrez y la mencionada composición eran nulos. Pero no sólo el origen de Tojo, sino también de otros fundos en el valle de Acoite, en la zona de Yungas argentinas, remiten a esa merced original otorgada a Pedro Montaño y a la posterior composición de $1647^{35}$.

Otro fundo que estaba anexo a la hacienda de Tojo tuvo un origen también polémico, con títulos disputados, en este caso con los indígenas originarios. Nos referimos a las tierras de Guanacuno o Guanaco-Huno en Sud Chichas (actual departamento de Potosí). En documentación mucho más tardía: una revisita efectuada por el gobierno republicano de Bolivia, en $1864^{36}$, y otra de los años 1901 y 1902 relativa a la ex vinculación de tierras de comunidad indígena ${ }^{37}$, consta que Guanaco Huno era un ayllu de la comunidad de Sococha que, al igual que la de Talina, había demostrado poseer títulos perfeccionados por composición, en 1646, de lo que resultaba «el antiguo

${ }^{33}$ Titulo de merced otorgado por Luis de Fuentes a favor de Juan Montaño de seis fanegadas de tierra de sembradio en Tojo, una estancia con extensión de una legua en Humchara, otra legua de terreno en Acoiti, veinte fanegadas en La Caldera, una estancia en Taxara, y el Huayco de Las Cañas con todas sus tierras, y la composición de la estancia de Humchara por Don Francisco de la Peña, AHJ-MT, carpeta 200, años 1580 y 1647.

${ }^{34}$ Idem.

35 Encontramos, en los estudios sobre el Marquesado, sólo una referencia parcial a la merced otorgada a Juan Montaño. Madrazo, 1982: 75, indica que las tierras de Acoite fueron recibidas por Juan Montaño, en 1580, en merced, y que «por composición pasó a Obando».

${ }^{36}$ Matricula general de la revisita practicada en la provincia de Sud Chichas, 1864, Archivo y Biblioteca Nacionales de Bolivia, Sucre, Bolivia (ABNB), Revista, 484..

37 Matricula general de contribuyentes de la provincia de Sud Chichas practicada por la comisión revisitadora de 1901-1902, ABNB, Revista, 489. 
pleito de la comunidad de Sococha con los propietarios del Yavi, Marquesado Campero» ${ }^{38}$.

La comunidad de Sococha quedaba ubicada entre dos de las más importantes haciendas del marquesado: Tojo y Yavi. La situación de la propiedad de esas tierras es algo confusa, pues las referencias que encontramos a ella en el período colonial son más específicas con respecto a la encomienda de indios que a la propiedad de los fundos. Zanolli, que ha estudiado exhaustivamente la encomienda de Humahuaca, refiere que San Rafael de Sococha y San Antonio de Humahuaca fueron, entre 1540 y 1698 los dos pueblos principales de reducción de dicha encomienda. De Sococha sostiene que surgió, a mediados de la década de 1550, como una chacra de españoles que perteneció primero a Juan de Villanueva y luego a su viuda Petronila de Castro (madre de Juan Ochoa de Zárate), encomenderos de Humahuaca, y lentamente se transformó en un pueblo de reducción ${ }^{39}$. También Zanolli nos informa que en tiempos en que Juan Ochoa de Zárate asumió la titularidad de la encomienda de Humahuaca, obtuvo en merced 30 fanegadas de tierras en el valle de Sococha, en $1593^{40}$. Recapitulando toda esta información, traigo a colación los lazos familiares que unían a la familia Zárate con Bernárdez de Ovando, a lo que debo agregar que éste último recibió, en 1636, una merced de tierras en «Yavi y altos de Sococha» ${ }^{41}$; pero, diez años después, la comunidad de Sococha legalizó los títulos de sus tierras por «composición» ${ }^{42}$. A este complicado panorama se suma que, durante la administración de Juan José Fernández Campero, el primer Marqués, éste adquiere por compra Yavi $\mathrm{Chico}^{43}$, que incluía 30 fanegadas de tierra en Sococha ${ }^{44}$. Para aclarar esta cuestión se hace necesario, en el futuro, proceder a una reconstrucción exacta de las tierras en cuestión. Por ahora sólo puedo afirmar que la disputa por esas propiedades llegó hasta el siglo XIX, cuando la porción de las posesiones de la comunidad de Sococha se encontraron rodeadas por las del Marquesado y las de otros terratenientes.

38 Informe de Féliz Ameller fechado el 28 de junio de 1902, citado en Antezana Salvatierra, 1996: 54. Sobre el proceso de ex vinculación de tierras de comunidad en Sud Chichas puede verse Teruel, 2007: 639-680.

39 Zanolli, 2005: 189

40 Ibidem: 130.

41 Albeck y Palomeque, 2009: 195.

42 Antezana Salvatierra, 1996: 51-55.

43 Madrazo, 1982: 36 y 74.

44 Inventario de los bienes que dejó al morir Juan José Fernández Campero de Herrera, Marqués del Valle de Tojo en el año 1718, AHJ-MT, carpeta 130. 
Yavi, Yavi Chico y Acoite

No menos complejo es reconstruir el origen de las tierras que conformaron el núcleo y residencia principal del Marquesado: la extensa hacienda de Yavi, con su casa señorial y hermosa capilla. Se trataba de una unidad compuesta de tierras agrícolas (chacras) y ganaderas (estancias) en una gran extensión a ambos lados de la actual frontera argentino-boliviana, con centro en la Puna de Jujuy (Yavi), extendiéndose hasta los valles próximos a Tarija (Camacho) y la zona alta de transición de la Puna a las Yungas (hoy departamento de Santa Victoria, en Salta).

Recientes estudios de Palomeque y de Albeck nos proporcionan información fundamental que echa nueva luz sobre la cuestión del origen de la propiedad de las tierras de la actual Puna jujeña, entre ellas las que luego integrarían el mayorazgo del Marquesado del Valle de Tojo ${ }^{45}$. En una apretada síntesis de la compleja historia que reconstruyen las autoras, y ateniéndonos sólo a las propiedades que nos ocupan en esta ocasión, traemos a colación que cuando el virrey Toledo ordenó la reducción de los chichas en tres pueblos de indios, en 1573:

[...] los pueblos chichas que vivían al norte de la actual Puna de Jujuy [...], aceptaron ser "reducidos" hacia Talina mientras mantenían sus derechos a las tierras de sus antiguos asentamientos (que eran Yoscaba, Escaya y un lugar denominado Cimsima que correspondería al actual Cerrillos). Su curaca, Don Diego Espeloca, obtuvo la merced sobre las antiguas tierras de los chichas [...] las que hacia el sur colindaban con la jurisdicción de la ciudad de Jujuy en $1593^{46}$.

Sostienen las autoras citadas que, luego de la fundación de la ciudad de Jujuy, en 1593, la Gobernación del Tucumán extendió su jurisdicción sobre el Norte de la Puna -más allá de «la raya del Tucumán» (límite con Charcas)- y entregó mercedes sobre tierras que desde Charcas habían sido reconocidas a los indígenas reducidos en Talina. A su vez, los herederos del cacique Espeloca vendieron algunas de las estancias que su antecesor había recibido en merced $^{47}$, tras lo cual tempranamente se impuso la propiedad privada en la Puna septentrional.

Algunos de los fundos que luego integrarán la hacienda de Yavi fueron parte de ese proceso de privatización de tierras indígenas: Sansana, Cerrillos o Chocoite, Cangrejos y Cangrejillos, Yoscaba y Escaya fueron compradas

45 Palomeque, 2010: 1-77. Albeck y Palomeque, 2009: 173-212.

46 Albeck y Palomeque, 2009: 183.

${ }^{47}$ Idem. 
por Bernárdez de Ovando a las poseedores de las mercedes; mientras que él mismo recibió, en 1636, la merced de una «estancia en los altos de Sococha y Yave» ${ }^{48}$. Por otra parte, la propiedad denominada Yavi Chico, que incluía tierras en Sococha, fue adquirida tras su muerte por su yerno, Juan José Fernández Campero ${ }^{49}$.

Al Sur de las tierras que habían pertenecido a los chichas de Talina, también en la actual Puna de Jujuy, se encontraban los pueblos de reducción de Casabindo y Cochinoca. La historia de estas posesiones es compleja, tal como ya lo había señalado Madrazo ${ }^{50}$, dado que se entrelaza con la encomienda de los indígenas de Casabindo y Cochinoca que, en 1654, obtuvo Pablo Bernárdez de Ovando. La confusa situación, según documentan Albeck y Palomeque, se originó en dos mercedes de tierras que incluían parte de las de reducción de sus encomendados. Se trata de la merced de Quebrada de la Leña, que Ovando recibió en 1655, a condición de dejar:

[...] como había de dejar y quedar para los indios naturales de los dichos sitios y pueblos que refiere en su pedimento, las tierras y aguas necesarias, según disposición de ordenanzas y en primer lugar siendo preferidos para sus chácaras, sementeras y pastos de sus ganados que tuvieren sin que les falta tierras para ello ${ }^{51}$.

A ello sumó, en 1662, otra gran extensión con la merced de San Joseph, que incluía a la mitad occidental de las tierras de reducción. La ambigüedad de esta situación, donde las tierras de los indígenas encomendados quedaban afectadas por dos mercedes recibidas por su encomendero, ocasionó problemas que trascendieron el período colonial desembocando en la rebelión de 1872-1874.

Finalmente, la gran hacienda de Yavi se extendía, hacia el Norte, hasta «la linde de Camacho», las fértiles tierras del río homónimo, en el actual departamento de Tarija (Bolivia), que a veces se computaban como anexas a la hacienda de La Angostura, y otras veces a la de Yavi. Se trataba de las tierras destinadas al cultivo del maíz en Chaguaya, Juntas y Chocloca, que a fines del siglo XVIII se encontraban en pleito con las familias Mealla y Alvarado ${ }^{52}$.

48 Ibidem: 195.

49 Madrazo, 1982: 36 y 74.

50 Ibidem: 1982: 35.

51 Merced de Quebrada de la Leña, 1655, citada en Albeck y Palomeque, 2009: 207.

52 Instrucción del Marques del valle de Tojo Don Martierena a su sobrino Francisco Martierena del Barranco sobre los pleitos que seguía en Tarija sobre Tierras, AHJ-MT, carpeta 119. Contracto de Inventario simple de todos los bienes y tierras comprendidos en los reinos de Tarija, Sin fecha i1784?, AHJ-MT, carpeta 143. 
Respecto a la porción Sur-oriental de Yavi, cuyo linde era el valle de Zenta, en el Inventario de los bienes que dejó al morir Juan José Fernández Campero de Herrera ${ }^{53}$, se menciona específicamente a Guacoia [Bacoya] y Poscaya, situados actualmente en el departamento de Santa Victoria, provincia de Salta (Argentina). Vecina a dichas posesiones se encontraba Acoite. Según informa Madrazo $^{54}$, esta propiedad fue incorporada a los bienes del Marquesado tras la muerte de Juan José Fernández Campero, durante la administración del Marqués consorte, Don Alejo Martierena del Barranco.

La historia de Acoite es compleja dado que había sido una de las posesiones de Bernárdez de Ovando que no legó a su sucesora Juana Clemencia sino a un hijo extramatrimonial, Miguel de Obando. Esa es la razón por la cual no la hallamos entre las que figuran en el inventario de las de Juan José Fernández Campero. Ahora bien, ¿cómo las adquirió Ovando? Madrazo afirma que por composición en $1646^{55}$. Pero Acoite había formado parte de esa extensa merced que otorgara Luis de Fuentes, en 1580, a Juan Montaño, que incluía «[...] las tierras en el pueblo y valle de Acoite en una legua en redondo con todo el riego que en dicho valle y pueblo hubiere con el pueblo viejo en medio» ${ }^{56}$. Al igual que en el caso de Tojo, ello abre el interrogante sobre el procedimiento, anterior a la composición, a través del cual llegó a manos de Bernárdez de Ovando.

Pasado el tiempo, ya en el siglo XIX, tanto Acoite, como Bacoya y Poscaya pasaron a formar parte de la gran hacienda de Santa Victoria, en Argentina.

\section{La Angostura}

La hacienda de viñas de La Angostura, ubicada en el valle del río Tarija, a pocos kilómetros al Sur de la ciudad, estaba dedicada a la producción de vino y aguardiente y era notoriamente la más importante de las posesiones del Marquesado.

${ }^{53}$ Inventario de los bienes que dejó al morir Juan José Fernández Campero de Herrera, Marqués del Valle de Tojo en el año 1718, documento inserto en otro caratulado Testimonio de la hijuela que se le formó a doña Juana Clemencia de Obando de los bienes de su herencia, 1619, AHJ-MT, carpeta 130.

${ }_{54}$ Madrazo, 1982: 36.

${ }^{55}$ Idem.

${ }_{56}$ Titulo de merced otorgado por Luis de Fuentes a favor de Juan Montaño..., Año 1580, AHJ-MT, carpeta 200. Estimo que la mención al «pueblo viejo» refiere a alguno de los asentamientos prehispánicos de mitmakunas de la región, que son señalados por Oliveto y Ventura, 2009: 129. 
La hacienda había formado parte de los bienes del capitán Juan García Bravo y, en 1662, salió a la venta en remate público, según estudios de Pres$\mathrm{ta}^{57}$. En ese momento

[...] se trataba de un complejo de haciendas, cuya unidad principal era nombrada "La Gloria" que concentraba a las plantaciones de vid, parrales, frutales, lagares, bodegas, viviendas del personal superior, capilla, oratorio y más las rancherías de los yanaconas. Cuatro estancias (San Agustín, Los Orozas, Taxara y Zuriaga) y dos haciendas de "pan llevar" (Calamuchita y San Gerónimo), conformaban este complejo productivo ${ }^{58}$.

La Angostura fue adquirida tras la muerte de Bernárdez de Ovando (que había sido acreedor de su anterior dueño), en el período en que su viuda, Ana María Mogollón, junto con su nuevo esposo, Pedro Ortiz de Santisteban, ejercían la tutela de Juana Clemencia ${ }^{59}$. Posteriormente la posesión de la hacienda originó un pleito entre Juan José Campero de Herrera, que la reclamaba como herencia de su esposa, y Pedro Ortiz de Santisteban ${ }^{60}$.

\section{El Marquesado en el siglo XIX}

A comienzos del siglo XIX el Marquesado, como unidad productiva, se encontraba en pleno funcionamiento. De los documentos que quedaron en su archivo se desprende una prolija contabilidad y control, tanto de la producción como del cobro de tributos y arriendos. Así vemos en un libro de Cuenta de cargo y data que lleva Don Miguel de Elizalde con el Señor Marquez del Valle de Tojo, desde el 27 de enero de $1807^{61}$, que el terrateniente recibe «charqui», «sebo colado», «sebo y grasa en oja», «sebo en vejigas», lenguas, cecina, suelas, cueros de vaca y «grasa negra». No hay mayor detalle respecto al vínculo de estas personas con el Marqués, sólo figuran sus nombres, pero estimo que se trataba de puesteros de las estancias ganaderas. Los ingresos por esos rubros en los años 1807 y 1808 eran de $\$ 7.526$, que adicionados al cobro de «otras deudas» ascendían a $\$ 10.704$, lo que implicaba una cuantiosa suma, equivalente al valor de importantes haciendas en esa época ${ }^{62}$.

57 Presta, 1989: 43-56.

58 Ibidem: 46.

59 Madrazo, 1982: 35-36.

${ }^{60} \mathrm{Al}$ respecto véase Presta, 1989: 46-47.

${ }^{61}$ Cuenta de cargo y data que lleva Don Miguel de Elizalde con el Señor Marquéz del Valle de Tojo, desde el 27 de enero de 1807, AHJ-MT, carpeta 81.

${ }^{62}$ Por ejemplo, unos de las más importantes propiedades en Jujuy, la hacienda de San Lorenzo, de 72.529 has. de propiedad de Gregorio de Zegada, estaba valuada a fines del siglo XVIII en \$10.000. Peirotti, 2014: 138. 
Otro tanto sucedía con el cobro de los tributos. Un padrón de los «indios originarios, tributarios de la encomienda del Señor Marqués [...] que residen en el curato de San Juan Bautista de Zerrillos, sus vice parroquias, anexos, ayllus y otros» ${ }^{63}$, del año 1806 , anota prolijamente nombre y apellido y el lugar donde se encontraban los «tributarios útiles». Quienes han estudiado el funcionamiento económico del Marquesado en tiempos coloniales ${ }^{64}$, destacaron el desplazamiento que se hacía de los indios de encomienda a diferentes propiedades, por lo que este documento nos sirve para ver la dispersión de estos indígenas en 1806. De un total de 581 tributarios «útiles» ${ }^{65}$, el $63 \%$ estaba en sus tierras de origen: en el Pueblo y Beneficio de Nuestra Señora de la Candelaria de Cochinoca (205 tributarios) y en el Pueblo de Nuestra Señora de la Asunción de Casabindo, vice parroquia de Cochinoca (164 tributarios). Otros residían en las haciendas de Yavi, Santa Victoria y Tojo: en la Vice parroquia de San Francisco de Yavi (61 tributarios), en el Anejo de Santa Victoria de Acoiti (44 tributarios) y en el Marquesado del Valle de Tojo y Beneficio y Doctrina de Livi-Livi, 72 tributarios. Una minoría, 35 tributarios, se encontraba en tierras de otros propietarios como agregados y/o arrenderos: en Rosario de los Cerrillos, Anexo de Amblayllo y Curato de San Pablo de Chiquana, en la jurisdicción de Salta.

\section{Los tiempos republicanos}

La revolución independentista puso fin al tributo indígena en $1810 \mathrm{y}$, en 1813, a la encomienda, la mita y el yanaconazgo, quitando un importante recurso de ingresos y mano de obra al IV Marqués, Juan José Feliciano Fernández Campero. La supresión del tributo implicaba el fin de la encomienda de Casabindo y Cochinoca, que había subsistido hasta inicios de la república, al igual que había perdurado el yanaconazgo en la jurisdicción de Charcas (no así en el Tucumán, donde había sido suprimido en el siglo

${ }^{63}$ Padrón general de la encomienda del Sr. Marqués del Valle de Tojo practicado por D. Francisco Poveda practicado como Apoderado fiscal de la revisita de Indios. Casabindo, Diciembre de 1806, AHJ-MT, carpeta 227.

${ }^{64}$ Madrazo, 1982. Palomeque, 1995: 13-48. Santamaría, 2001.

${ }^{65}$ El número de «tributarios útiles» de esta fuente coincide aproximadamente con el de los tributarios varones adultos de la Matricula de la encomienda del Marqués de 1806, cuyo original del Archivo General de la Nación, Argentina, 13, 17-2-2- L.3, fue transcrito por Palomeque, 1995: 40. Dicho documento registra 580 tributarios varones adultos en un total de 2.534 personas que incluyen otras categorías (reservados, próximos, niños y niñas, viudas, solteras, casadas, caciques, ausentes). 
XVII). Sin embargo, una década después de la abolición, encontramos que algunas de las personas que estaban por contraer matrimonio en la vice parroquia del Valle de Tojo, entre los años 1821 a 1823, habían sido registradas por el vicario como «indio de la encomienda de Sococha», «indio de la encomienda de Yavi», «indio tributario», «indio yanacona», o «indio libre» ${ }^{66}$.

Madrazo fue el primero en señalar que en las primeras décadas del siglo XIX el Marqués dejó de cobrar tributos para pasar a cobrar arriendos a los indígenas de Casabindo y Cochinoca en sus propias tierras, pero sin dar más detalles de cómo se produjo esa trasmutación ${ }^{67}$. La cuestión también produjo la inquietud a Doucet, quien refiere a ello como un «singular, fascinante y desconcertante caso de "mutación institucional" $\gg{ }^{68}$, que quizás pudiera haber sido preparada por los mismos Marqueses a finales del siglo XVIII, cuando la encomienda estaba ya en su última vida, o durante la Guerras de la Independencia, tras la abolición del tributo. Destaca que los Marqueses «avezados alquimistas o ingenieros de transformaciones institucionales, según las conveniencias de los tiempos, convirtieron a arrenderos en tributarios o a ex tributarios en arrenderos» ${ }^{69}$.

En la medida en que las guerras de la independencia con España alteraron el normal funcionamiento económico y los circuitos mercantiles, sumado a la decadencia de la minería potosina, acelerada a partir de 1811, y a los efectos de la guerra en una región que durante quince años fue asolada por los ejércitos beligerantes, el arriendo fue convirtiéndose en uno de los recursos más importantes del gran terrateniente. Madrazo calcula, en base a registros de las tres primeras décadas del siglo XIX unos 1.750 arrendatarios en las posesiones del Marquesado en la Puna de Jujuy y en Acoite (Santa Victoria), más otros 100 en Sococha, sin contabilizar a los de Tojo y La Angostura ${ }^{70}$. Una lista de arrendamientos comprendidos entre los años 1813 a 1816, perteneciente a las propiedades de Yoscaba y «la Puna», contabiliza 324 arrendatarios (estimo que cada uno representaba a una familia), que pagaban en moneda, en plata, en trabajo y/o en productos tales como picote, ovejas, grasa, vacas, sal, jerga,

${ }^{66}$ Habitantes de las jurisdicciones de la vice parroquia del valle de Tojo, informan al vicario y juez eclesiástico su determinación de casamiento para que se labre las actuaciones pertinentes para verificar su soltura y libertad, años 1821,1822 y 1823, AHJ-MT, carpeta 80.

${ }_{67}$ Madrazo, 1982: 139-169.

${ }^{68}$ Doucet, 2002: 270.

${ }^{69}$ Ibidem: 271. Sobre la relación de tierras y tributos en la Puna de Jujuy en el siglo XIX puede verse el interesante trabajo de Gil Montero, 2002: 227-255, comentado por Doucet.

${ }^{70}$ Madrazo, 1982: 160. 
corderos, burros, etc., permitió rendir al Marqués la suma de $\$ 4.484^{71}$. Otra lista de «deudores», tanto de arriendos como de pago por productos recibidos (por ejemplo un «cesto de coca»), es la «del valle para el año $1810{ }^{72}$. Lo interesante de ella es que, en algunas ocasiones, figuran los lugares en que residían las personas sujetas al Marqués. Pudimos ubicar en Santa Victoria: Bacoya, Poscaya, Lizoite, Acoiti; en las vecinas tierras de Tarija, en Arce: Mecoya y Maramulo; en Yunchara: Quebrada Honda y Papachacra. En Omiste, Lampazo (Livi-Livi), Guanacouno (Moraya, vice cantón Sococha) y Salitre (Sococha). El documento termina con el encargo a «Don Gervasio Antonio Molina el cobro de los sugetos contenidos en las lista antecedente, para que los exija con la eficacia que acostumbra sin permitir quede alguno. Yavi, junio 12 de $1816{ }^{73}$.

Un universo de «arrenderos» o «colonos» poblaban, trabajaban y pagaban renta en los dominios del Marquesado en el siglo XIX. Este régimen implicaba que, además de pagar el canon de derecho de pastaje o por parcelas de cultivo, se debía satisfacer la «obligación de servicio personal» de proporcionar mano de obra al propietario una determinada cantidad de días, según se pactara. Este sistema de prestaciones serviles fue común en todo el ámbito rural. Suprimido expresamente, tanto por la Asamblea del Año 1813, como por decretos dictados por la provincia de Jujuy en 1836 y 1845, continuó practicándose hasta entrado el siglo XX. En Bolivia, a pesar de leyes y decretos que, desde 1825 insistieron en prohibir toda obligación de servicio personal, el sistema se mantuvo, con variantes, hasta la Revolución de $1952^{74}$.

\section{El fin del Marquesado y del vínculo de Tojo}

El último propietario del mayorazgo del Marquesado del Valle de Tojo fue Fernando Campero Barragán, quien, ya en tiempos republicanos, no pudo

${ }^{71}$ Cuenta y razón de los ingresos rurales de la casa del señor Coronel Mayor Marques don Juan José Campero, Marques del Valle de Tojo, a cargo de don José Antonio Ruiz, desde el año 1813 hasta 1819, AHJ-MT, carpeta 65. Estas listas fueron estudiadas también por Conti y Santamaría, 1994: 123-142.

${ }_{72}$ Lista del valle para el año 1810, AHJ-MT, carpeta 68.

${ }^{73}$ Idem.

${ }^{74}$ Sobre la abolición del trabajo gratuito de los colonos en la legislación boliviana republicana puede verse Antezana, 2006: 75-80. La pervivencia de la práctica puede constatarse en los documentos y en una variedad de estudios sobre el agro boliviano antes de la Revolución Nacional (véase por ejemplo Paz Ballivián, 2009: 19-49). En cuanto a la legislación y la práctica respecto a la «obligación de servicio personal» en la provincia Argentina de Jujuy, puede verse un estudio de mi autoría: Teruel: 1991: 11-126. 
ostentar el título nobiliario. Nació en Potosí en 1809 y fue bautizado en la iglesia de Tojo.

Desatadas las guerras de independencia, su padre, el IV Marqués, Juan José Feliciano Fernández Campero, dejó de apoyar a las tropas «realistas» para pasar a militar en las huestes «patriotas», pero cayó prisionero y fue sometido a una corte marcial por infidencia. Doucet narra la suerte posterior del Marqués: le confiscaron todos sus bienes y lo despacharon a Lima. Si bien luego obtuvo el perdón de Fernando VII y la devolución de los bienes confiscados, fue enviado a España en calidad de exiliado y murió en Jamaica, en 1820 , en una escala del trayecto ${ }^{75}$.

Su hijo primogénito, Fernando Campero Barragán, estudió leyes en Sucre, fue dos veces senador de la República de Bolivia y candidato a la presidencia. Heredó las posesiones del Marquesado que, a partir de 1825, quedaron divididas en dos Estados nacionales: Argentina y Bolivia. Pocos años después, en 1831, el Código Civil boliviano suprimió los mayorazgos, aunque permitió que sus detentores conservaran los bienes vinculados hasta su muerte, cuando debían ser legados en mitades, una a su «inmediato sucesor», la otra a los demás herederos. En Argentina, la situación en que quedaron los mayorazgos fue una especie de «limbo constitucional», al decir de Doucet, dado que si bien la Asamblea de 1813 había prohibido nuevas fundaciones, nada estableció sobre los ya existentes ${ }^{76}$.

Los tiempos republicanos trajeron, además, otras novedades: la supresión del yanaconazgo, del tributo ${ }^{77}$ y de la encomienda, todo lo cual erosionaba el poderío del antiguo Marquesado, ya bastante debilitado a consecuencia de las guerras de independencia y de la confiscación temporaria de sus bienes. Sin embargo la economía del Marquesado pudo recuperarse gracias a que el nexo entre las provincias del Alto Perú (actual Bolivia) y las del Norte Argentino se reorganizó a través de una compleja red de negocios, cultura y familia que iba más allá de las limitaciones fronterizas. Los estudios de base dedicados a reconstruir estas redes y circuitos comerciales sostienen que hubo una reactivación desde $1825^{78}$, aunque alterada por las guerras civiles argentinas y la desatada con la Confederación Peruano-Boliviana (1836-1839). En esta última contienda, Fernando Campero Barragán tuvo un destacado papel intentando

75 Doucet, 2006: 6.

76 Ibidem: 7.

77 En el recientemente creado Estado boliviano, el Mariscal Sucre reestableció el pago del tributo, en 1826, pero se trataba ahora de una contribución que los indígenas pagaban al Estado, y desde la presidencia de Santa Cruz se vinculó cada vez más con el derecho a las tierras comunales.

78 Al respecto puede consultarse Langer y Conti, 1991: 91-112. 
propiciar la incorporación de la Puna de Jujuy a la vecina y recientemente formada Confederación.

En sus últimos años de vida Fernando Campero Barragán debió enfrentar un pleito con la provincia de Jujuy (Argentina) por las tierras de Casabindo y Cochinoca, que puso fin a su dominio sobre ellas. Ya habíamos mencionado que los Marqueses impusieron el cobro de arriendo sobre las tierras de reducción de los indígenas de su otrora encomienda de Casabindo y Cochinoca, situación que se mantuvo sin modificaciones hasta 1872. En ese año, los «arrenderos» presentaron ante el gobernador de Jujuy un reclamo cuestionando la legitimidad de los títulos de Fernando Campero Barragán sobre dichos fundos. El gobierno provincial sostuvo, entonces, que durante la colonia la encomienda no originaba derechos sobre la tierra, y decretó la expropiación de Casabindo y Cochinoca. Tras ello se desencadenó una ola de denuncias similares en toda la Puna, cuyos pobladores comenzaron un alzamiento en reclamo de lo que consideraban derechos adquiridos durante la colonia.

El enfrentamiento entre campesinos indígenas y terratenientes se entrecruzó con luchas políticas relativas a las adhesiones manifestadas a nivel provincial en la sucesión de la presidencia de la nación, alineando a los bandos en pugna a favor de los propietarios, uno, y de los indígenas arrendatarios, el otro. La rebelión desencadenada, que finalizó con la intervención de tropas nacionales y la derrota de los indígenas en la batalla de Quera, en 1875, ha dado lugar a una abundante producción historiográfica ${ }^{79}$, por lo que acá sólo trataremos sus consecuencias sobre la propiedad. Nos interesa destacar que en el medio del conflicto, cuando Fernando Campero apeló ante la Suprema Corte de Justicia de la Nación, sólo presentó la documentación relativa a la merced de encomienda y la concesión del título de Marqués del Valle de Tojo a su antecesor, Juan José Fernández Campero, con lo que, forzadamente, intentaba demostrar sus derechos a las tierras en cuestión. Me llama la atención que no hubiese argüido a su favor aquellas dos mercedes que había recibido Bernárdez de Ovando en el siglo XVII (Quebrada de la Leña y Estancia San Joseph) superpuestas a las tierras entregadas a los pueblos de Casabindo y Cochinoca. ¿Por qué razón no presentó dicha documentación? Es de suponer que tales mercedes no habían sido confirmadas a su debido tiempo. Finalmente, la Suprema Corte de Justicia de la Nación declaró, en 1877, a las tierras de Casabindo y Cochinoca propiedad del fisco jujeño. El fallo sostenía que las tierras concedidas durante la colonia para la subsistencia de los indígenas eran de dominio directo de la Corona y que «por consecuencia de su emancipación

\footnotetext{
79 Varios autores han abordado el tema desde diferentes ópticas, citamos acá los primeros trabajos de Madrazo, 1982: 139-176. Fidalgo, 1988: 1-116. Paz, 1991: 63-89.
} 
y del régimen político que se dio, han pasado por derecho de reversión al dominio de la Provincia» ${ }^{80}$.

Así, en el último tercio del siglo XIX, las tierras del antiguo Marquesado se habían reducido notoriamente del lado argentino: la expropiación en la Puna significaba la pérdida de unas 600 mil hectáreas. Sin embargo, una extensión similar se mantenía en manos de Campero, especialmente en sus haciendas principales: Yavi, en Jujuy, y Santa Victoria, en Salta ${ }^{81}$.

Cuadro 3. Propiedades de Fernando Campero en Argentina en 1876 y 1878

\begin{tabular}{|c|c|c|c|}
\hline \multicolumn{2}{|c|}{ Provincia de Salta } & \multicolumn{2}{c|}{ Año 1876 } \\
\hline Departamento & Propiedad & $\begin{array}{l}\text { Valor fiscal } \\
\text { \$boliviano }^{82}\end{array}$ & Hectáreas \\
\hline Santa Victoria & Santa Victoria & 30.000 & 223.496 \\
\hline Yruya & Valle Delgado & 7.500 & 8.000 \\
\hline \multicolumn{2}{|c|}{ Provincia de Jujuy } & \multicolumn{2}{c|}{ Año 1878 } \\
\hline Yavi & Yavi & 110.000 & 225.000 \\
\hline Santa Catalina & Yoscaba & 36.000 & 65.323 \\
\hline Perico del Carmen & Perico de San Juan & \\
\hline
\end{tabular}

Fuentes: elaborado en base al Catastro de las propiedades urbanas y rurales de la provincia de Jujuy, Año 1878, AHJ-MT. Catastro de la propiedad territorial y patente de molinos del Departamento de Santa Victoria, 1876 y Catastro de la propiedad territorial y moviliaria de Iruya, 1876, Archivo Histórico de Salta, Salta, Argentina.

${ }^{80}$ Fallo de la Corte Suprema de Justicia de la Nación. La Provincia de Jujuy contra D. Fernando Campero, sobre reivindicación. Buenos Aires, Abril 21 de 1877. Reproducido en Carrasco, 2000: 209-218.

${ }^{81}$ Lamentablemente los catastros de propiedad de las provincias argentinas de Jujuy y de Salta no proporcionan información sobre superficie, por lo cual hube de recurrir a otras fuentes. La superficie de Valle Delgado y de Santa Victoria fue tomada de Roboratti, 1998: 163-170 y corresponde a las dimensiones de las fincas hacia mediados del siglo XX. Las dimensiones de la hacienda de Yavi fueron extraídas de un informe oficial del año 1925 (Salmoral, 1925). La superficie de Yoscaba se calculó en base a información de Paz, 1995: 224-225, y corresponde a fines del siglo XIX.

${ }^{82}$ El peso boliviano fue la moneda corriente en el Norte argentino. En Jujuy hasta inicios de la década de 1880 el presupuesto provincial se hacía en esa moneda.

${ }^{83}$ Perico de San Juan fue comprada por Fernando Campero a la familia Iriarte en la década de 1870 . 
Fernando Campero falleció en 1883 y dejó en su testamento los bienes ubicados en Bolivia a los hijos de su primer matrimonio con Tomasa de La Peña Santa Cruz, y los de Argentina a su joven viuda en segundas nupcias (la salteña Corina Aráoz Valverde) e hijos ${ }^{84}$.

A diferencia de lo que había ocurrido en Argentina, en Bolivia las propiedades del antiguo Marquesado habían subsistido prácticamente íntegras, según se desprende del inventario de los bienes que quedaron en Bolivia tras la muerte de Campero (cuadro 4).

\section{Cuadro 4. InVEntario REALIZAdo En 1892 de las PRopiedades DejadAs por Fernando CAmpero Barragán en Bolivia}

\begin{tabular}{|l|c|c|}
\hline Propiedades & Valor en bolivianos* & Colonos \\
\hline FINCA DE SAN MATEO & $\mathbf{2 2 . 8 8 0}$ & \\
\hline FINCA DE SAN PEDRITO & $\mathbf{2 . 1 0 0}$ & \\
\hline LÍNEA DE TOJO & 42.240 & 89 \\
\hline El colorado & 20.200 & 82 \\
\hline Hornos y Rupasca & 6.666 & 48 \\
\hline Santa Ana y la Echisera & 5.150 & 15 \\
\hline Quebradillas & 5.516 & 30 \\
\hline Huvilla Farada Honda [¿Quebrada Honda?] & 10.660 & 38 \\
\hline Papa Chacra & 7.500 & 46 \\
\hline Escapana & 12.000 & 28 \\
\hline FINCA DEL SALITRE PARTIDO DE SOCOCHA & 9.616 & 101 \\
\hline Yana Alpa & 17.000 & 75 \\
\hline Salitre & 15.966 & 80 \\
\hline Tincuya y Cangrejillos & 4.340 & 19 \\
\hline Huanaco-huno & 6.713 & 49 \\
\hline Total de las fincas de Tojo y Salitre & $\mathbf{1 6 3 . 6 5 7}$ & $\mathbf{7 0 0}$ \\
\hline HACIENDA DE LA ANGOSTURA & 43.864 & \\
\hline Angosto del Marquez & 26.000 & \\
\hline Serro del viento & 500 & \\
\hline
\end{tabular}

${ }^{84}$ Testamento de Fernando Campero, transcrito por Doucet, 1993: 114-119 del original que consta en el Archivo Histórico de Salta, Salta, Argentina (AHS), Protocolos Notariales, carpeta 80, protocolo 667 . 


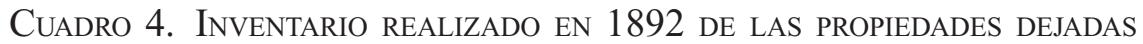 por Fernando Campero Barragán en Bolivia (Continuación)}

\begin{tabular}{|l|c|c|}
\hline Propiedades & Valor en bolivianos* & Colonos \\
\hline Campo de corral de Piedras & 10.408 & \\
\hline Pampa grande de Calamuchita [con dos casas] & 26.966 & \\
\hline El Paraiso o terreno de la Sra. Carmen Campero & 3.597 & \\
\hline Pampa de Villa & 600 & \\
\hline Potrero de los Mulatos & 2.000 & \\
\hline Tunalcillo, Garnicayo y Cañadas & 3.500 & \\
\hline Vallecito i Hioque & 5.500 & \\
\hline El Monte & 3.500 & \\
\hline Laderas & 3.000 & \\
\hline Las Lomas de Suriava & 2.500 & $\mathbf{9 0}$ \\
\hline Total de la Angostura & $\mathbf{1 3 1 . 9 3 5}$ & 107 \\
\hline FINCA DE LA HUERTA. (casa hacienda) & 38.730 & 125 \\
\hline Chaguaya. & 3.580 & $\mathbf{1 6}$ \\
\hline Mecoya y Marañuelo [¿Maramulo?] & 30.000 & 16 \\
\hline Total de La Huerta & $\mathbf{7 2 . 3 1 0}$ & \\
\hline FINCA DE TOLDOS & & \\
\hline Arasay, Vallecito y Lipeo & 3.000 & 2.000 \\
\hline Serro de san José [maderas] & 1.500 & \\
\hline Río de Sivingal [despoblada, bosque y pastos] & $\mathbf{6 0 0}$ & \\
\hline Total de Toldos & & \\
\hline
\end{tabular}

Fuente: elaborado en base a Expediente de inventario y partición de los bienes dejados por Fernando Campero en Bolivia, Archivo notarial de Jacqueline A. de Arce, Tarija, Bolivia (AnJAA), expediente Campero, documentos protocolizados, 1883. Transcrito en Langer y Bass Werner de Ruiz, 1988: 431-448.

* Destacado en mayúsculas las propiedades principales, respetando los nombres de los fundos tal como están consignados en la transcripción de la fuente, proponiendo entre corchetes las aclaraciones necesarias. Los comisionados y los peritos representantes de los propietarios fijaron el valor de las propiedades en base a una estimación de su renta, incluyendo las casas, las herramientas, bodegas, molinos, ganado y cultivos, tanto del terrateniente como de sus colonos.

Me interesa destacar la continuidad territorial de las propiedades en cuestión: hacia el Este las tierras de Tojo lindaban con La Huerta (Chaguaya y 
Mecoya), esto es aproximadamente desde el Río San Juan de Oro hasta el Río Camacho. Más allá, hacia el Noreste se encontraba La Angostura. Al Oeste, Tojo tenía por límite la comunidad de Sococha y colindaba hacia el Sur con la hacienda de Yavi, y al Suroeste con Toldos y Santa Victoria, en Argentina ${ }^{85}$. Era un enorme dominio, no sólo de territorio sino también de personas; si tenemos en cuenta que los 1.052 colonos que registra el inventario, en Bolivia, equivalían a otras tantas familias, podría tratarse de más de 4.000 personas en 1892. A modo de tener un parámetro de cuán significativa era esa cifra, traigo a colación el censo de población del año 1901: en las provincias tarijeñas de mayor dominio territorial del Marquesado, Avilés tenía 10.275 habitantes y Aniceto Arce 8.67786.

Se trataba de una gran concentración de riqueza, aún en una época que ya no era la de su esplendor. Para ilustrarlo mencionaré con más detalle algunos de los bienes inventariados en la hacienda de Tojo en 1892. El núcleo principal estaba constituido por la casa hacienda con cincuenta habitaciones, capilla anexa y bodega con cinco cubas y alambique ${ }^{87}$, carpintería y herrería. En los terrenos de cultivo anexos a la hacienda había grandes cantidades de árboles frutales, por ejemplo más de 8.000 plantas de durazno, además de parras, manzanos, perales, higueras, limoneros, membrillos, olivos y nogales. En sus campos se criaban 32.973 cabezas de ganado mayor y menor.

${ }^{85}$ Según se consigna en el Inventario, los «Linderos generales de las fincas de Tojo y Salitre. Son por el E. con la finca de la Huerta que divide la Cordillera, por el O. el seno San Miguel, y la comunidad de Sococha y los Escalieres y Arrayas por el S. con la República Arjentina, por el Norte con las propiedades de la Sra. Petrona Trigo, y los propietarios del Cantón Yunchará i tiene una extensión de mas o menos de 1.240 kilómetros cuadrados». Respecto a la «Casa y hacienda de la Huerta en el vice cantón de Rosario de Camacho. Sus linderos en general de todos los inmuebles avaluados, son: por el Este con propiedad del Doctor Virjinio Lema; por el Norte con Doña Beatriz Trigo, i con Doña Petrona Trigo viuda de Vasquez, divido por el rio de la huerta i el cerro de Minas: por el oeste con la finca de Tojo i por el Sur con propiedades de Doña Corina viuda de Don Fernando Campero, ubicadas en la república Arjentina». Para la de la finca Toldos: «Sus linderos son por el este con los Ricices y Juan Manuel Coca, por el oeste con la finca de Santa Victoria o limiti de la república Arjentina dividido por la Cordillera del Serro Bravo, por el Sur con el rio Lipeo limite de la República arjentina propiedad de Doña Corina Valverdi viuda de Campero, y por el Norte con las propiedades de Deidamia Castillo». Expediente de inventario y partición de los bienes dejados por Fernando Campero en Bolivia, transcrito en Langer y Bass Werner de Ruiz, 1988: 439-443.

${ }^{86}$ Censo General de la Población de la República de Bolivia, Cochabamba, Edit. Canelas S.A, 1973.

${ }^{87}$ La bodega más importante se hallaba en La Angostura, con 15 cubas. 
Cambios económicos de fines del siglo XIX

La muerte de Fernando Campero Barragán y el consiguiente fin del mayorazgo coincidieron con un giro en las políticas de Bolivia y Argentina, que venía reafirmándose desde la década de 1870, y produjo cambios que llevaron a reemplazar definitivamente los patrones económicos heredados de la colonia. La moneda feble, principal articuladora de los circuitos comerciales que habían unido el Norte argentino con Bolivia, fue suprimida por el gobierno boliviano produciendo una progresiva iliquidez. Si bien la Guerra del Pacífico (1879-1883) actuó momentáneamente como revitalizador de los circuitos tradicionales con el Noroeste argentino, el tendido del ferrocarril a Antofagasta llevó poco después a que los centros mineros del Altiplano se conectaran con el mercado mundial a través de esta vía, desechando la intermediación de los comerciantes salto-jujeños con los puertos del litoral Atlántico argentino ${ }^{88}$.

Además ya las condiciones habían cambiado; en Bolivia, se agotaba el ciclo de la plata para dar paso al del estaño, a la vez que para la región tarijeña se abría un nuevo mercado con la reciente colonización de las tierras chaqueñas ${ }^{89}$. En Argentina la política proteccionista a la producción azucarera del Norte argentino, que buscaba compensar el desequilibrio que el modelo agro exportador producía entre las provincias pampeanas y las del interior, creaba las condiciones necesarias para que la economía regional revertiera sus tendencias: de la circulación y conexión con el mercado boliviano y chileno, a la producción e integración con el mercado nacional como productor de azúcar ${ }^{90}$.

Así las últimas décadas del siglo XIX, paulatinamente, presenciaron el fin de aquellos circuitos comerciales de los que se servía y a los que proveían las producciones de los fundos del Marquesado, base de su prosperidad en tiempos coloniales y en buena parte del siglo XIX. En la provincia argentina de Jujuy (al igual que en Salta y Tucumán) los ingenios azucareros fueron adquiriendo una importancia que definiría a la región prontamente como productora de azúcar, produciendo una satelización de otros espacios en su torno. La Puna jujeña y su borde pedemontano fueron desplazadas económicamente quedando como regiones marginales y, en definitiva, proveedoras de mano de obra.

\footnotetext{
${ }^{88}$ Langer y Conti, 1991: 105-112.

${ }^{89}$ Langer y Bass Werner de Ruiz, 1988: XIII.

${ }^{90}$ Campi y Richard Jorba, 1999: 376-377.
} 
Las propiedades del antiguo Marquesado a comienzos del siglo XX

¿Qué se conservó de la gran estructura territorial del antiguo Marquesado luego del fin del mayorazgo? ¿Cuál fue su impronta en las estructuras agrarias regionales de las primeras décadas del siglo XX? Para responder a una parte de estas preguntas, hemos rastreado la genealogía de los descendientes de Fernando Campero Barragán (ver Anexo), e individualizado los fundos que conservaron en el Sur de los departamentos de Tarija y de Potosí, en Bolivia, y en las provincias de Jujuy y Salta, en Argentina.

\section{Las propiedades de la familia Campero en Bolivia}

Los catastros de propiedad de las provincias de Aniceto Arce y José María Avilés (Tarija, 1906), y de Sud Chichas (Potosí, 1909) ${ }^{91}$, brindan la posibilidad de individualizar la mayoría de los fundos que quedaron en manos de los herederos de Fernando Campero Barragán ${ }^{92}$. En el cuadro 5 procedo a sintetizar dicha información para luego analizar cada caso.

\section{El patrimonio territorial en Tarija}

El principal centro agrícola productivo del antiguo Marquesado, La Angostura, quedó en posesión de Fernando Campero Arce (hijo de Juan José Campero y Mercedes Arce Trigo) y en 1898 fue vendido ${ }^{93}$. En el catastro de 1906 estaba registrado a nombre de José Arce, pero según información que brinda la propia familia Campero ${ }^{94}$, para esa época el titular de la propiedad era Luis Paz Arce. En ese entonces La Angostura tenía el valor más alto de toda la región tarijeña de estudio: era un importante productor de

${ }^{91}$ Provincia de Arce. Registro de las fincas rusticas, 1906, ABNB, Tarija, 2; Provincia de Avilés. Registro de fincas rusticas, 1906, ABNB, Tarija, 12, 12a, 12b, 12c. Potosí. Registro de fincas, 1909, ABNB, Potosí, 13. Dichos catastro fueron analizados en su totalidad dos trabajos previos de mi autoría: Teruel, 2007: 639-680; 2014: 1-33.

${ }_{92}$ No mencionaré acá aquellas fincas ubicadas fuera de esos distritos, entre las que San Mateo era la única importante.

${ }^{93}$ Agradezco al evaluador anónimo la información relativa a la sentencia de la Corte Suprema de Sucre (1892) sobre el «Juicio Célebre de la familia Campero», que dejó La Angostura en manos de Fernando Campero Arce, así como la posterior venta a Beatriz Trigo, viuda de Aráoz.

94 Campero Paz, 2007: 77. 
Cuadro 5. Propiedades conservadas por los descendientes de Fernando Campero Barragán en las provincias de Avilés, Arce y Sud Chichas (Bolivia 1906 y 1909)

\begin{tabular}{|c|c|c|c|c|}
\hline \multicolumn{5}{|c|}{ Departamento Tarija } \\
\hline $\begin{array}{l}\text { Provincia } \\
\text { y cantón }\end{array}$ & Propiedad & $\begin{array}{l}\text { Valor } \\
\text { bol. }\end{array}$ & Hectáreas & Colonos \\
\hline \multirow{5}{*}{$\begin{array}{l}\text { Avilés } \\
\text { Yunchara }\end{array}$} & $\begin{array}{l}\text { Tojo (fracción), Fernando Campero } \\
\text { Arce }\end{array}$ & 80.000 & 2.037 & 114 \\
\hline & $\begin{array}{l}\text { Buena Vista de Tojo, Alfredo Campero } \\
\text { Arce }\end{array}$ & 56.000 & 6.000 & 140 \\
\hline & $\begin{array}{l}\text { Quebrada Honda y fracción de Tojo } \\
\text { Andrés Aráoz, esposo de Rosalía Cam- } \\
\text { pero Arce }\end{array}$ & 40.000 & 5.000 & 30 \\
\hline & $\begin{array}{l}\text { San Cristóbal y una parte de Tojo. } \\
\text { José Campero Arce }\end{array}$ & 40.000 & 1.000 & 98 \\
\hline & Chorcoya, Julio Campero Vásquez & 6.000 & 1.000 & 0 \\
\hline \multirow{2}{*}{$\begin{array}{l}\text { Avilés } \\
\text { Concepción }\end{array}$} & $\begin{array}{l}\text { Calamuchita (fracción), Napoleón Vás- } \\
\text { quez, casado con Casimira Campero }\end{array}$ & 8.000 & 28 & 8 \\
\hline & $\begin{array}{l}\text { Chorrillos, Aviles. Mercedes Arce } \\
\text { Trigo, viuda de Campero }\end{array}$ & 12.000 & 978 & 17 \\
\hline \multirow{4}{*}{$\begin{array}{l}\text { Arce } \\
\text { Chaguaya }\end{array}$} & Mecoya y Maramulo. Samuel Campero & 50.000 & 87.500 & 135 \\
\hline & $\begin{array}{l}\text { La Huerta. Casimira Campero de la } \\
\text { Peña, casada con N. Vázquez }\end{array}$ & 50.000 & 37.500 & 39 \\
\hline & $\begin{array}{l}\text { Canchas Mayo. Carmen Vásquez, } \\
\text { hija de Casimira Campero y Napoleón } \\
\text { Vásquez }\end{array}$ & 12.000 & 3.000 & 35 \\
\hline & Chaguaya. Samuel Campero & 5.000 & 400 & 0 \\
\hline $\begin{array}{l}\text { Arce } \\
\text { Toldos }\end{array}$ & $\begin{array}{l}\text { Santa Rosa de Lipeo. Napoleón } \\
\text { Vásquez, casado con Casimira } \\
\text { Campero }\end{array}$ & 7.000 & 87.500 & 13 \\
\hline \multicolumn{5}{|c|}{ Departamento Potosí } \\
\hline $\begin{array}{l}\text { Sud } \\
\text { Chichas } \\
\text { Moraya }\end{array}$ & $\begin{array}{l}\text { Salitre. Mercedes Arce, viuda de } \\
\text { Campero }\end{array}$ & 35.000 & 2.000 & 40 \\
\hline TOTALES & & 401.000 & 233.943 & 669 \\
\hline
\end{tabular}

Fuentes: elaborado en base a ABNB. Registro de las fincas rusticas de 1906 de las provincias de Arce y Avilés; y Registro de las fincas rusticas de 1909 de la provincia de Sud Chichas. 
aguardiente y sus 25.200 has contenían terrenos de excelente calidad ${ }^{95}$. La familia Campero sólo conservó de la antigua hacienda de La Angostura una fracción de Calamuchita, y, en el mismo cantón de Concepción, otra propiedad denominada Chorrillos.

El mayor dominio territorial que mantuvieron los herederos del Marquesado a comienzos del siglo XX estaba centrado en la antigua zona de poblamiento del fértil valle del río Camacho, en el cantón Chaguaya, a unos $60 \mathrm{~km}$ de la ciudad de Tarija. Allí, tres de sus sucesores poseían en total 128.400 has en 1906, lo que significaba el $84 \%$ de la superficie del cantón registrada en el catastro $^{96}$. Samuel Campero había heredado Mecoya, Maramulo y Chaguaya, mientras que su hermana, Casimira Campero, La Huerta; propiedades cuya administración habían delegado a un comerciante. Más de 200 colonos residían en estos fundos, lo que redundaba en una importante producción agrícolaganadera: se trataba de los mayores productores de papa, de ganado mayor y menor del cantón. Todo ello se traducía en un alto valor, el $39 \%$ del total del cantón Chaguaya ${ }^{97}$.

En la región alto andina, al Este del río Sococha-San Juan de Oro, cuatro nietos de Fernando Campero (descendientes de su fallecido hijo, Juan José Campero de la Peña, y Mercedes Arce Trigo) conservaron gran parte de las tierras de Tojo. Los cinco herederos sumaban 15.037 has, lo que significaba el $30 \%$ de la superficie del cantón Yunchara y el 51\% del valor del total de propiedades del mismo. Allí se concentraba una importante cantidad de colonos que proporcionaban a los terratenientes una renta en dinero y en productos, además de trabajadores. Los 382 colonos que habitaban las distintas fracciones en las que se había dividido la hacienda de Tojo tenían distintas obligaciones, dependiendo éstas del grado mayor o menos de explotación directa por parte del propietario. Por ejemplo, los que poblaban las tierras en propiedad de Fernando Campero Arce, aptas para el cultivo de maíz, trigo, papas y alfalfa, pagaban por sembradío y por pastaje, tenían dos días de obligación de trabajo en reparación de la hacienda «para evitar el perjuicio del río, un día en la cosecha, y otro cuando se practicaba rodeo», varios eran además «arrenderos de algunos árboles de la viña de la hacienda» o «del producto de árboles de durazno, peramotas, manzanos, higueras $\rangle^{98}$. Pero la mayoría de los colonos eran pastores de ovejas, cabras y llamas. En las cinco fracciones en que quedó

\footnotetext{
95 Provincia de Avilés. Registro de las fincas rusticas, 1906, ABNB, Tarija, 12.

96 Teruel, 2014: 13-14.

${ }_{97}$ Provincia de Arce, Registro de las fincas rusticas, 1906, ABNB, Tarija, 2.

${ }_{98}$ Provincia de Avilés. Registro de fincas rusticas 1906. Convenios entre propietarios y colonos. Avilés, 1906, ABNB, Tarija, 14 y 14a.
} 
divida la hacienda se criaban 144.000 cabezas de ganado menor, y si bien la fuente no me permite discriminar que cantidad de estos animales pertenecían al terrateniente, se hace evidente que mientras mayor cantidad de colonos había, el número de ganado ascendía. Tanto en estas propiedades de las tierras altas de Yunchara, como en la de los valles en Chaguaya, la producción directa recaía fundamentalmente en los colonos, quienes transferían al propietario del fundo una renta en proporción a la cantidad de ganado que criaban o a la superficie de tierra que labraban.

En contraste, en el cantón de Toldos, la zona selvática de Yungas, el colonato era poco significativo, lo que se explica por varios factores. Se trataba de una región de frontera, hasta comienzos del siglo XIX con los indígenas chiriguanos ${ }^{99}$, por lo tanto de reciente colonización, y con mayores posibilidades de acceso a la tierra para los pobladores humildes. Como herencia de la familia Campero se mantenía la extensa finca de Santa Rosa de Lipeo, la que tardíamente aparece individualizada como propiedad en los registros de los bienes del Marquesado ${ }^{100}$. Con sus 87.500 has (casi el $70 \%$ de la tierra catastrada en el cantón Toldos) ${ }^{101}$, esta propiedad estaba en gran parte despoblada, tenía sólo 13 colonos, que sin obligaciones de trabajo pagaban al propietario tanto por cultivo como por pastaje.

Unas décadas después, en 1938, cuando se hizo efectivo el tratado de límites internacionales de 1925 entre Argentina y Bolivia, el cantón Toldos se incorporó a Argentina como parte del departamento de Santa Victoria, en Salta. Para ese entonces, la familia Campero ya había vendido la finca ${ }^{102}$.

99 Fernando Cornejo, quien siguió a cargo del viaje de Adrián Fernández Cornejo desde la reducción de Zenta, narra en 1791 que pasando el arroyo Baritú, encontró, sobre el Bermejo, unos «pescaderos» hechos de piedra por los indios chiriguanos. Más adelante, pasando el arroyo Los Toldos, encontraron un pueblo llamado Cuyambuyo, de indios chiriguanos amigos. Allí recibieron la visita de Cuñarecuá, capitán de otro pueblo llamado Emborosú. Fernández Cornejo, 1971 [1791]: 82.

${ }^{100} \mathrm{La}$ encontramos por primera vez entre los bienes del Marquesado en el Expediente de inventario y partición de los bienes dejados por Fernando Campero en Bolivia, An-JAA, transcrito en Langer y Bass Werner de Ruiz, 1988: 439-443. Gil Montero, 2005: 125-157, sostiene que todo el valle de Toldos hasta Baritú había pertenecido al tarijeño Francisco Gutiérrez del Dozal, fallecido en 1815.

101 Provincia de Arce, Registro de las fincas rusticas, 1906, ABNB, Tarija, 2.

102 Reboratti, 1998: 73. 


\section{En Potosí}

A diferencia del departamento de Tarija, en el de Potosí permaneció la propiedad comunitaria indígena hasta 1901, cuando se llevó a cabo la desamortización en Sud Chichas (que en esa época abarcaba la actual provincia de Omiste). Como resultado de la ex vinculación se registró en el cantón Moraya, donde se hallaba el vice cantón de Sococha, 1.167 indígenas propietarios de parcelas de cultivo ${ }^{103}$. A la par, en todo el cantón había otros 212 propietarios de tierras privadas ${ }^{104}$. Entre ellos estaba Mercedes Arce Trigo, viuda de Campero, dueña de 2.000 has con 40 colonos en Salitre, lo que en el conjunto de la propiedad de la zona ya resultaba un dominio poco relevante en comparación con lo que había significado en tiempos del Marquesado ${ }^{105}$.

\section{Propiedades del antiguo Marquesado en Argentina}

Los bienes de Fernando Campero Barragán, radicados en Argentina, quedaron en manos de su joven viuda, Corina Aráoz Valverde y de sus hijos aún menores. Se trataba de dos extensas e importantes haciendas: Yavi y, colindante hacia el Este, Santa Victoria. Del destino de sus otras propiedades sabemos que la hacienda de Yoscaba, en la Puna jujeña, fue vendida, tres años después de la muerte de Campero, en fracciones a sus arrendatarios. Fuera de la región de la Puna, la última propiedad que había adquirido Campero, en la década de 1870, Perico de San Juan (en los valles jujeños) fue dejada en manos de Justino Campero Valverde, hijo de la unión de hecho con Vicenta Valverde ${ }^{106}$.

Veamos entonces las características de las dos propiedades más importantes legadas en Argentina. Santa Victoria era una región cuyos campos servían de invernada de ganado, con gran conexión con la Puna de Jujuy y las vecinas tierras de Bolivia, desde y hacia donde se practicaba la trashumancia. Según el catastro del año 1876, en todo el departamento de Santa Victoria había 52 propiedades ${ }^{107}$, con valuación muy pequeña comparada con la finca homóni-

${ }^{103}$ Matrícula general de contribuyentes de la provincia de Sud Chichas practicada por la comisión revisitadora de 1901, ABNB, Revistas, 489. Más detalles sobre la ex vinculación en Sud Chichas pueden verse en Teruel, 2007: 639-680.

${ }^{104}$ Registro de Propiedades Rústicas de Sud Chichas, 1909, ABNB, Potosí, 13.

${ }^{105}$ Yanalpa, otro de los fundos del Marquesado anexo a Salitre, aparentemente había sido enajenado, pues en 1909 estaba a nombre de Eliseo Wayar.

106 Campero Paz, 2007: 185.

107 Catastro de la propiedad territorial y patente de molinos del Departamento de Santa Victoria, 1876, AHS. 
ma, que controlaba el $62 \%$ del valor de total departamental. La mayoría de la población no tenía acceso a la propiedad y era arrendataria de Campero. Tras su muerte, la finca quedó en manos de Corina Aráoz de Campero y en 1934 la heredó su hija: Hortensia Campero.

Corina Aráoz recibió también Yavi. En 1925, en tiempos en que era su propietaria, una comisión gubernamental relevó los latifundios existentes en la Puna de Jujuy ${ }^{108}$, e informo que dicha hacienda, con 225.000 has, cubría casi la totalidad del departamento homónimo y criaba 67.279 ovejas, 6.220 llamas y 4.634 burros. Vivían allí 998 arrenderos (régimen equivalente al de colono en Bolivia) dedicados al pastoreo y a las labores de la tierra, que solían emigrar, en invierno, a trabajar en la zafra de los ingenios azucareros mientras los niños y mujeres de la familia cuidaban del ganado. Administrativamente la finca estaba dividida en los siguientes rodeos:

1. Yavi: 100 arrenderos agrícolas.

2. Yavi Chico: 123 arrenderos agrícolas.

3. Sansana: 106 arrenderos.

4. Barrios: 81 arrenderos (54 agrícolas y 27 ganaderos).

5. Cangrejilos: 89 arrenderos (65 agrícolas y 24 de pastoreo).

6. Cangrejos: 19 arrenderos (8 agrícolas y 11 de pastoreo).

7. Cholacor y Chaguaymayo: 34 arrenderos (10 agrícolas).

8. Escaya y Abra Colorada: 54 arrenderos (23 de ellos con pequeños cultivos).

9. Cara Cara y Pulpera: 101 arrenderos (9 con pequeños cultivos).

10. Chocoite, Cacanaite y Pozuelos: 88 arrenderos (39 con pequeños cultivos).

11. Corral, Blanco y Escobar: 64 arrenderos (8 agrícolas).

12. Suripugio: 66 arrenderos (33 agrícolas).

La hacienda se mantuvo en manos de la familia pues a Corina Aráoz le sucedió su hija, Hortensia Campero. Ambas propiedades compartieron una historia común, que originó uno de los episodios más conflictivos de la historia agraria del Noroeste argentino. En 1920 Corina Aráoz de Campero arrendó Santa Victoria al ingenio azucarero San Martín del Tabacal, situado en Salta, que la requería en una estrategia para asegurarse mano de obra, exigiendo a los arrenderos que pagaran sus cánones con el trabajo en la zafra, bajo pena de ser desahuciados si se negaban ${ }^{109}$. En 1930 corrió la misma suerte Yavi

\footnotetext{
108 Salmoral, 1925: 16-35.

109 Rutledge, 1987: 181-204.
} 
y la situación se mantuvo hasta 1949, cuando el presidente Perón ordenó su expropiación, junto con la de otros latifundios de la región ${ }^{110}$. Dicho decreto no afectó a Santa Victoria, allí Hortensia Campero continuó arrendando la finca al ingenio hasta la década de 1960, época hasta la que se mantuvo el uso compulsivo de los arrendatarios en la zafra azucarera. En esos tiempos la finca tenía 2.700 arrendatarios ${ }^{111}$.

\section{CONSIDERACIONES FINALES}

La reconstrucción del patrimonio territorial del Marquesado del Valle de Tojo, considerando los cambios ocurridos en sus propiedades en el curso de tres siglos, fue una compleja y necesaria tarea a fin de sopesar la incidencia de esta arquitectura colonial en las estructuras agrarias regionales.

Es de notar que la estructura territorial del Marquesado se mantuvo casi íntegra hasta el último tercio del siglo XIX cuando, coincidentemente con el fin del mayorazgo, la legitimidad de los títulos sobre parte de sus tierras comenzó a ser cuestionada en Jujuy. Hemos demostrado que el origen de sus posesiones deja bastantes aspectos en una zona oscura, lo que originó varios pleitos con otros propietarios particulares que no parecieron ocasionar merma en su patrimonio territorial. No ocurrió lo mismo cuando el conflicto involucró a antiguas comunidades indígenas y, en definitiva, a los intereses fiscales del Estado republicano, puntualmente el gobierno de la provincia de Jujuy, que esgrimió la teoría de la reversión de derechos de la Corona española a su favor. Llama la atención que en Bolivia las propiedades de Campero no se pusieran en entredicho, quizás porque el grueso de las mismas se hallaba en Tarija, una región exenta de propiedad comunal indígena y, por ende, de los conflictos los relativos a la ex vinculación a fines del siglo XX y principios del XX. Por otra parte, no debemos olvidar la posición de Fernando Campero Barragán en la sociedad boliviana; no sólo se trataba de un hombre económicamente poderoso, sino destacado en el plano político, dos veces senador, e incluso candidato a la presidencia.

Tras su muerte, las sólidas redes sociales tejidas durante largo tiempo sostuvieron el dominio familiar y una posición encumbrada, especialmente en Tarija. Si atendemos a la información proporcionada por los catastros de

110 Decreto del Poder Ejecutivo Nacional expropiando las tierras de la Quebrada y Puna de Jujuy, 1 de agosto de 1949, en Tanco, 1949: 24. En esa instancia, se registró la superficie de la hacienda de Yavi en 100.000 has.

111 Reboratti, 1998: 175. 
propiedad, podemos afirmar que al comenzar el siglo XX, se conservaban en manos de la familia directa en Bolivia 233.943 has. La rama familiar argentina conservaba en Yavi y en Santa Victoria alrededor de 400.000 y había perdido y enajenado más de 600.000 entre las de Yoscaba y los supuestos y cuestionables derechos sobre Cochinoca y Casabindo.

El notorio dominio territorial tuvo su correlato en un poderío ejercido sobre buena parte de la población de la región, donde la herencia del Marquesado fueron relaciones que conservaban visos de servidumbre bajo las formas del colonato y del arriendo, prácticas que si bien no eran de su exclusividad, encontraban garantizada su continuidad en un modelo de hacienda asentado en el gran dominio territorial que obtenía sus rentas fundamentalmente de los campesinos colonos/arrenderos. Salvo La Angostura y sus tierras circundantes, donde posteriormente se desarrollaron varias de las actuales modernas bodegas tarijeñas, las demás propiedades del Marquesado no llegaron a originar en el siglo XX centros productivos de importancia, dejando como impronta en la memoria de los pobladores el esplendor de «los tiempos del Marqués», a la vez que relatos de la expoliación. En las estructuras agrarias de inicios del siglo XX, la herencia del Marquesado, otrora centro de amplios circuitos regionales de producción e intercambio, encarnó la marginación frente a los nuevos proyectos y modelos económicos nacionales, especialmente en la Argentina agroexportadora.

\section{Anexo: Descendencia de Fernando Campero Barragán ${ }^{112}$}

Matrimonios:

$1^{\circ}$. Con Tomasa de La Peña Santa Cruz.

Hijos:

- Juan José, casado con Mercedes Arce Trigo.

- Samuel, casado con Julia Vásquez Trigo.

- Casimira, casada Andrés Molina Saracho y con Napoleón Vásquez.

- Manuel, casado con Mercedes Echazú Suárez.

$2^{\circ}$. Con Corina Aráoz Valverde, en 1864.

Hijos:

- Octavio (muere soltero).

- Julio (Obispo de Salta).

- Hortensia, casa con Virgilio Figueroa Salguero.

112 Elaborado en base a Campero Paz, 2007: 1-269. 
$3^{\circ}$. De la relación amorosa con Vicenta Valverde.

Hijos:

- Natividad.

- José Manuel.

- Justino.

- Dominga.

- Vicenta.

\section{BIBLIOGRAFÍA}

Albeck, Mariette y Palomeque, Silvia, "Ocupación española de las tierras indígenas de la Puna y 'Raya del Tucumán' durante el temprano período colonial”, Memoria Americana, 17/2 (Buenos Aires, 2009): 173-212.

Antezana, Luis E., La política agraria en la primera etapa nacional, La Paz, Plural, 2006.

Antezana Salvatierra, Alejandro, Los liberales y el problema agrario en Bolivia (1899-1920), La Paz, Plural, 1996.

Assadourian, Carlos Sempat, "Agricultura y tenencia de la tierra antes y después de la conquista", Población y Sociedad. Revista Regional de Estudios Sociales, 12/13 (Tucumán, 2006): 3-56.

Bisio, Raúl y Forni, Floreal, "Economía de enclave y satelización del mercado de trabajo rural. El caso de los trabajadores con empleo precario en un ingenio azucarero del Noroeste Argentino", Desarrollo económico, 16 (Buenos Aires, 1976): 3-56.

Campero Paz, Javier, El vínculo de Tojo, Tarija, Edit. Luis de Fuentes, 2007.

Campi, Daniel y Richard Jorba, Rodolfo, "Las producciones regionales extrapampeanas", Marta Bonaudo (dir.), Nueva Historia Argentina. Liberalismo, Estado y Orden burgués (1852-1880), vol. IV, Buenos Aires, Sudamericana, 1999: 363-422.

Carrasco, Morita, Los derechos de los pueblos indígenas en Argentina, Buenos Aires, Vinciguerra, 2000.

Conti, Viviana y Santamaría, Daniel, "Mecanismos de intercambio en períodos de transición: el caso de los arrendamientos en dos estancias de la Puna jujeña (1813-1816)", Anuario del Instituto de Estudios Americanos, LI/1 (Sevilla, 1994): 123-142. 
Doucet, Gastón, “De Don Juan José Feliciano Fernández Campero a Fernando Campero. Apuntes documentales y críticos al estudio de la sucesión del Marquesado del Valle de Tojo en el siglo XIX “, Revista de la Academia Argentina de Ciencias Genealógicas, LII/26 (Buenos Aires, 1993): 3-133.

Doucet, Gastón, "Perduración y transformaciones de los pueblos de indios coloniales, sociedades indígenas y economías coloniales en el Tucumán colonial. Cometarios", Judith Farberman y Raquel Gil Montero (comps.), Los pueblos de indios del Tucumán colonial: pervivencia y desestructuración, Bernal, Universidad Nacional de Quilmes y EDIUNJu, 2002: 257-274.

Doucet, Gastón, "Los Campero y el Marquesado del Valle de Tojo", Revista Fundación Campero, 1 (Tarija, 2006):1-8.

Fernández Cornejo, Adrián, "Descubrimiento de un nuevo camino desde el valle de Centa hasta la villa de Tarija. 1791", Pedro de Angelis, Colección de Obras y Documentos [1º ed.1836], Buenos Aires, Plus Ultra, 1971, vol. VII: 73-87.

Fidalgo, Andrés, ¿De quién es la Puna?, Jujuy, 1988.

Fleitas, María S. y Teruel, Ana A., "Política y movilización campesina en el norte argentino. La cuestión de la tierra indígena en el proceso de ampliación de la democracia", Revista Andina, 45 (Cuzco, 2007): 41-61.

Gentile, Margarita, "El Maestre de Campo Don Pablo Bernárdez de Obando. Su certificación de méritos y filiación", Chungara, 26/2 (Arica, 1994): 211-232.

Gil Montero, Raquel, "Tierras y tributos en la Puna de Jujuy. Siglos XVIII y XIX", Judith Farberman y Raquel Gil Montero (comps.), Los pueblos de indios del Tucumán colonial: pervivencia y desestructuración, Bernal, Universidad Nacional de Quilmes y EDIUNJu, 2002: 227-255.

Gil Montero, Raquel, "Poblaciones de frontera. Los Toldos en los siglos XIX y XX", Anuario de Estudios Bolivianos, Archivísticos y Bibliográficos, 11 (Sucre, 2005): $125-157$.

Langer, Erick y Bass Werner de Ruiz, Zulema, Historia de Tarija. Corpus documental. vol. V., Tarija, Universidad Autónoma Juan Misael Saracho, 1988.

Langer, Erick y Conti, Viviana, "Circuitos comerciales tradicionales y cambio económico en los Andes centromeridionales (1830-1930"), Desarrollo Económico, 31/121 (Buenos Aires, 1991): 91-112.

Madrazo, Guillermo B., Hacienda y encomienda en los Andes. La puna argentina bajo el Marquesado de Tojo, siglos XVII a XIX, Buenos Aires, Fondo Editorial, 1982. 
Mariluz Urquijo, José M., "Los Mayorazgos", Lecciones y Ensayos. Instituto de Historia del Derecho Ricardo Levene, 42 (Buenos Aires, 1970): 139-173.

Oliveto, Guillermina y Ventura, Beatriz, “Dinámicas poblacionales de los valles orientales del sur de Bolivia y norte de Argentina, siglo XV-XVII. Aportes etnohistóricos y arqueológicos", Población y Sociedad, 16 (Tucumán, 2009): 119-150.

Palomeque, Silvia, "Intercambios mercantiles y participación indígena en la Puna de Jujuy a fines del período colonial", Andes. Antropología e Historia, 6 (Salta, 1995): 13-48.

Palomeque, Silvia, “La 'historia' de los señores étnicos de Casabindo y Cochinoca (1540-1662)", Andes. Antropología e Historia, 17 (Salta, 2006): 139-193.

Palomeque, Silvia, "Los chichas y las visitas toledanas. Las tierras de los chichas de Talina (1573-1595)", Surandino Monográfico, segunda sección del Prohal Monográfico, 1/2 (Buenos Aires, 2010): 1-77.

Paz Ballivián, Danilo, Estructura agraria boliviana, La Paz, Plural, 2009.

Paz, Gustavo, "Resistencia y rebelión campesina en la Puna de Jujuy, 1850-1875", Boletín del Instituto de Historia Argentina y Americana Dr. Emilio Ravignani, Tercera serie/4 (Buenos Aires, 1991): 63-89.

Paz, Gustavo, “Tierra y resistencia campesina en la Puna de Jujuy, 1875-1910”, Andes. Antropología e Historia, 6 (Salta, 1995): 209-234.

Peirotti, Leonor, Una trama familiar. Trayectoria política y patrimonial de las ZegadaVillar en Jujuy, San Salvador de Jujuy, Ediunju, 2014.

Presta, Ana María, "Mano de obra en una hacienda tarijeña en el siglo XVII: La Viña de "La Angostura", F. Gonzalo Izquierdo (ed.), Agricultura, trabajo y sociedad en América Hispana, Santiago, Universidad de Chile, 1989: 43-56.

Presta, Ana María, “'Hermosos, fértiles y abundantes'. Los valles centrales de Tarija y su población en el siglo XVI", Stephan Beck, Narel Paniagua y David Preston (eds.), Historia, ambiente y sociedad en Tarija, La Paz, Universidad Mayor de San Andrés, 2001a: 25-39.

Presta, Ana María, "Mayorazgos en la temprana historia colonial de Charcas: familias encomenderas de La Plata, Siglo XVI", Raíces. Revista del Instituto boliviano de genealogía, LII/1 (La Paz, 2001b): 140-154.

Quesada Elías, Juan Isidro, "Los Marqueses de Casa Palacio en Charcas", Raíces. Revista del Instituto boliviano de genealogía, LII/1 (La Paz, 2001): 129-139.

Reboratti, Carlos, El Alto Bermejo. Realidades y Conflictos, Buenos Aires, La Colmena, 1998.

Rutledge, Ian, Cambio agrario e integración. El desarrollo del capitalismo en Jujuy, Tucumán, ECIRA-CICSO, 1987. 
Salmoral, Dámaso, Los Latifundios de la Puna. Informe de la Comisión encargada de estudiar dicho problema. Ley $N^{\circ}$ 588, Jujuy, Imprenta del Estado, 1925.

Santamaría, Daniel, Memorias del Jujuy colonial y del Marquesado de Tojo, Sevilla, Universidad Internacional de Andalucía, 2001.

Sica, Gabriela, "Tierras indígenas, tierras de españoles en la Quebrada de Humahuaca. Una historia de larga duración. Siglos XVII-XVIII", XXI Jornadas de Historia Económica, Caseros, Buenos Aires, 2008: 1-25.

Tanco, Miguel A., Redención del altiplano jujeño, Buenos Aires, Senado de la Nación, 1949.

Teruel, Ana, A., "Regulación legal del trabajo en haciendas, ingenios y plantaciones de caña de azúcar en la provincia de Jujuy, siglo XIX a mediados del XX", Daniel Campi (ed.), Estudios sobre la Historia de la Industria Azucarera Argentina, Jujuy, Universidad Nacional de Tucumán-Universidad Nacional de Jujuy, 1991: 99-126.

Teruel, Ana A., "La desamortización de la propiedad comunal indígena: pervivencias y transformaciones en la estructura agraria de la provincia de Sud Chichas", Anuario de Estudios Bolivianos, Archivísticos y Bibliográficos, 13 (Sucre, 2007): 639-680.

Teruel, Ana A., "Concentración y fraccionamiento de la propiedad agropecuaria de Tarija (Bolivia) a comienzos del siglo XX”, Daniel Vacaflores (ed.), Nuestra Tierra. Miradas a los procesos de construcción, administración y acceso al territorio en Tarija, Salta y Jujuy, Tarija, La Pluma del Escribano, 2014: 1-33.

Zanolli, Carlos E., Tierra, encomienda e identidad: Omahuaca (1540-1636), Buenos Aires, Sociedad Argentina de Antropología, 2005.

Fecha de recepción: 11 de julio de 2014.

Fecha de envío de las modificaciones: 25 de septiembre de 2014.

Fecha de aceptación: 15 de octubre de 2014. 


\section{The Tojo Valley Marquisate: legacy and mayorazgo between the seventeenth and twentieth centuries in Bolivia and Argentina}

The purpose of this article is the long-term reconstruction of the territorial characteristics of the Tojo Valley Marquisate (Marquesado del Valle de Tojo), an extensive region that covered land on both sides of the present-day Argentine-Bolivian border. The analysis will cover the origins and early formation of the land entailment (mayorazgo) of the Marquisate between the early eighteenth century and the last third of the nineteenth century, when the mayorazgo was dismantled. The essay ends with an evaluation of the historical impact of the Marquisate on the agrarian structures of southern Bolivia and northern Argentina in the early twentieth century. The research is based on documentation from the Marquesado del Valle de Tojo Archive, land titles from post-independence Bolivia and Argentina, qualitative sources, and published secondary material. Taken together, these sources allow us to analyse the territorial characteristics of the Marquisate and its legacy throughout the region.

KeY words: Marquesado del Valle de Tojo; Tojo Valley Marquisate; property; Argentina; Bolivia; land tenure; agrarian transformations. 